\title{
Rotational effects on exchange flows across a submerged sill
}

\author{
A. Cuthbertson ${ }^{1}$ (D) J. Berntsen ${ }^{2} \cdot$ J. Laanearu ${ }^{3} \cdot$ Magdeli Asplin $^{2}$
}

Received: 25 May 2020 / Accepted: 12 January 2021 / Published online: 18 February 2021

(c) The Author(s) 2021

\begin{abstract}
This paper presents new laboratory-scale numerical simulations of density-driven exchange flows generated across an idealised, submerged sill obstruction under both non-rotating and rotating frames of reference using the Bergen Ocean Model (BOM), a three-dimensional general ocean circulation model. Initial non-rotating BOM simulations are compared directly with previous laboratory data obtained in a large-scale channel facility incorporating an idealised trapezoidal sill. These laboratory experiments demonstrate that the saline intrusion flux across the sill is initially reduced and then eventually fully blocked under increasing net-barotropic flow conditions imposed in the counterflowing upper freshwater layer, with the saline blockage also more evident for reduced sill submergence depths. These parametric dependences are also demonstrated in the equivalent BOM simulations of the non-rotating sill exchange flows, although the numerical model results tend to overpredict both the interfacial velocity and density gradients across the sill (as indicative of suppressed interfacial mixing), as well as the fresh-saline source flux ratio at which full blockage of the saline intrusion occurs. The BOM simulations are then extended to consider rotating sill exchange flow dynamics. In particular, these additional runs demonstrate that Coriolis forces increase the overall blockage of the saline intrusion layer compared to equivalent non-rotating exchange flows, especially when the Rossby number associated with the saline intrusion flow across the sill is considerably less than unity. This effect is largely attributed to the development of Ekman boundary layer dynamics and associated secondary circulations within the bi-directional exchange flows. These are shown to impose strong control on the transverse distribution and extent of the lower saline intrusion flow across the sill and, hence, the parametric conditions under which full saline intrusion blockage is achieved in rotating sill exchange flows.
\end{abstract}

Keywords Sill exchange flow $\cdot$ Density-driven overflows $\cdot$ Dynamic blocking $\cdot$ Lab-scale modelling $\cdot$ Numerical simulations $\cdot$ Ocean modelling

A. Cuthbertson

a.j.s.cuthbertson@dundee.ac.uk

Extended author information available on the last page of the article 


\section{Introduction}

Restricted density-driven exchange flows are generated in oceans, seas and coastal margins when adjacent water bodies with different densities are connected by narrow channels or straits (e.g. Gibraltar, Bosphorus, Baltic Sea), or where natural topographic obstructions such as submerged sills control the intrusion of saline water into fjordic basins (e.g. Norway, Scotland) or oceanic deep-water outflows (e.g. Faroe Bank Channel). As well as providing hydraulic control of the internal flow conditions, these topographic features exert considerable influence on the lateral distribution of the flowing water masses, the internal mixing processes and the secondary circulations generated by uni or bi-directional exchange flows that develop as a result of horizontal density differences (i.e. baroclinic forcing) and/or pressure gradients (i.e. barotropic forcing) between adjacent water masses.

In the context of fjordic exchange flows, the presence of a submerged sill can generate a region of restricted exchange (RRE) whereby the partial blockage of tidal intrusions can lead to the suppression of deep water renewal, circulations and mixing in semi-enclosed fjordic basin, with contaminant accumulation and the formation of hypoxic bottom waters $[1,2]$. A recent study by Cuthbertson et al. [3] showed the flow dynamics of the dense saline water intrusion across a submerged sill to be controlled primarily by the relative magnitude of the volumetric fluxes within the upper (fresh) and lower (saline) layers, as well as the topography of the sill itself (i.e. relative sill submergence depth). This study also defined specific parametric conditions under which full blockage of the saline intrusion across the sill was observed. It also demonstrated that the primary blockage mechanism was driven by interfacial mixing and mass transfer (i.e. entrainment) from the bottom saline intrusion layer under dominant, net-barotropic, flow conditions in the upper freshwater layer. The main physical mechanism for this mass transfer was the development of shear-layer interfacial instabilities and overturning events that were quantified by calculation of the shear layer thickness (i.e. isopycnal separation) and the corresponding Thorpe overturning length scales [4].

Shear-induced interfacial mixing within stratified flows, resulting in fluid entrainment/ detrainment between counterflowing fluid layers, depends on the buoyancy flux and the relative strength of the outflowing upper freshwater layer. This can result in significant depthwise variations and strong gradients within both the velocity and density fields, leading to high gradient Richardson numbers (e.g. [5, 6]) where stable stratification and inhibited turbulent mixing are observed at the interface. In some cases, strong vertical entrainment is observed in the region of salt-water return flow [i.e. arrested salt-wedge condition, Sargent and Jirka [6]]. Under other stratified flow conditions, where gradient Richardson numbers are typically less than $1 / 4$, interfacial waves form along the density interface, with evolving interfacial instabilities (e.g. Kelvin-Helmholtz or Holmboe instabilities) providing additional mechanisms for vertical mixing across the density interface. Previous experimental studies have investigated the generation of interfacial waves in two-layer stratified exchange flows over submerged sills, in order to determine the influence of barotropic forcing [7] and boundary roughness [8], as well as to define the specific conditions under which Kelvin-Helmholtz instabilities are generated [9].

For submerged channels and sills that are relatively wide in comparison to the internal Rossby radius of deformation, Earth rotation effects associated with Coriolis accelerations would also be expected to introduce geostrophic adjustment of these internal fluid motions [10]. In terms of these geophysical flow applications, a particular area of interest is therefore associated with the behaviour of bi-directional exchange flows that develop over 
submerged sills to determine the effects of both sill geometry (i.e. relative submergence depth) and Earth rotation on the lateral distribution of the counter-flowing water masses, interfacial mixing processes, and secondary flow generation. Previous studies [11, 12] of bottom dense water flows along submerged, converging and upsloping V-shaped channels indicated that the confining channel topography and rotation effects have a strong influence on both the water mass flow distribution and associated density structure (e.g. isopycnal pinching and stretching) of the outflow along and across the channel. Other studies have also shown that rotation effects can suppress turbulent mixing generated at the interface [13] and lead to the development of Ekman layers that induce secondary, cross-channel circulations [14-16], even in straight rectangular channels [17].

Thus, in restricted bi-directional stratified flow problems, the internal flow dynamics are expected to be sensitive to (i) the dimensions of the obstruction (e.g. sill length, height and submergence depth), (ii) the density (and stratification) differences between the two water bodies separated by the sill; (iii) external barotropic forcing conditions due to the saline intrusion and freshwater outflows across the sill (e.g. [3, 7, 9]), and (iv) the Coriolis acceleration effects due to Earth rotation (e.g. [11-14, 18]).

As yet, however, topographic controls and the effects of rotation on the nature of interfacial mixing and secondary circulations generated by bi-directional stratified flows across a submerged sill are not fully understood and remain to be investigated thoroughly in a parametric manner through combined experiments and numerical modelling. In particular, the range of parametric conditions under which restricted exchange flows are initiated, or indeed blocked, is not yet completely understood. This has significant implications for improving our understanding of the intrusion of saline marine waters and the flushing of semi-enclosed estuarine impoundments, fjords and regional seas [19, 20]. As such, the current study presents new numerical simulations, firstly, of the non-rotating experimental data presented in Cuthbertson et al. [3], using the Bergen Ocean Model (BOM) at an equivalent laboratory-scale, before extending these BOM simulations to determine the effect of rotation on exchange flow dynamics across the sill. In particular, this study aims to delineate the relative importance of the Earth's rotation, barotropic forcing in the counterflowing fresh and saline water layers, and the sill submergence depth in defining the range of parametric conditions under which partial or complete blockage of saline intrusions across submerged sills will occur.

\section{Numerical model and model set-up}

The Bergen Ocean model (BOM) [21] is a terrain-following $\sigma$-coordinate numerical simulation tool for ocean modelling, discretized on a staggered C-grid. A fully non-hydrostatic version of BOM is applied in the present laboratory scale studies, while previous investigations of large-scale dense water flows (e.g. [22-24]) have utilised a hydrostatic version of the model. The non-hydrostatic capabilities of the model have also been demonstrated extensively [25-27], while Berntsen et al. [14] compared numerical model outputs directly to measurements of dense water flow down a canyon within a laboratory-scale rotating tank. The BOM has also been applied to investigate tidal mixing and exchange flow processes across submerged sills and through sea straits (e.g. [27-29]). For the advection of density and momentum, a Total Variance Diminishing (TVD) scheme with a superbee limiter [30] is applied. 


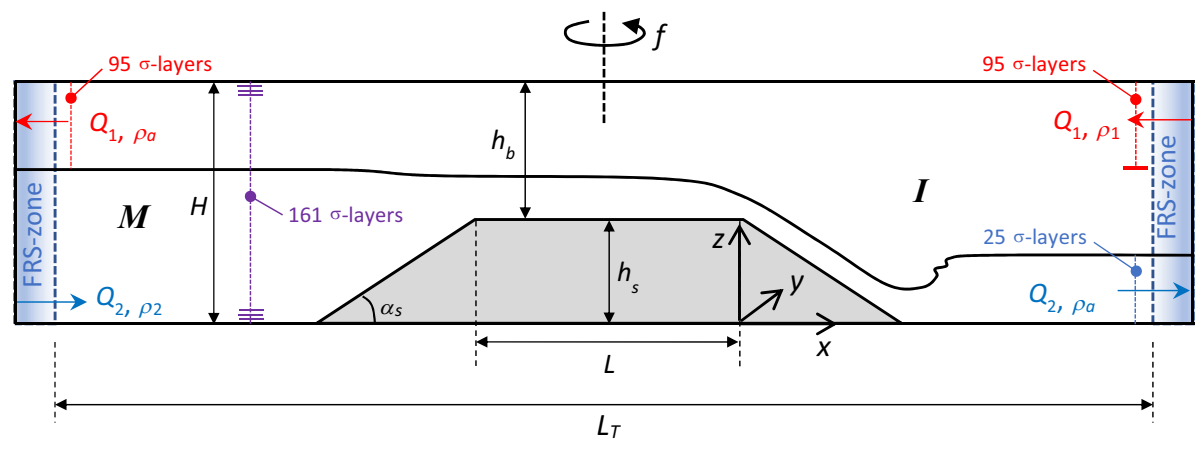

Fig. 1 Schematic representation of the BOM channel-sill model domain

Fig. 2 Ramp up of volume flux ratio $Q^{*}\left(=Q_{1} / Q_{2}\right)$ values over duration of numerical experiments [blue values are for experiments (Run 2, Table 1) + equivalent BOM simulations; green values are for BOM simulations only]

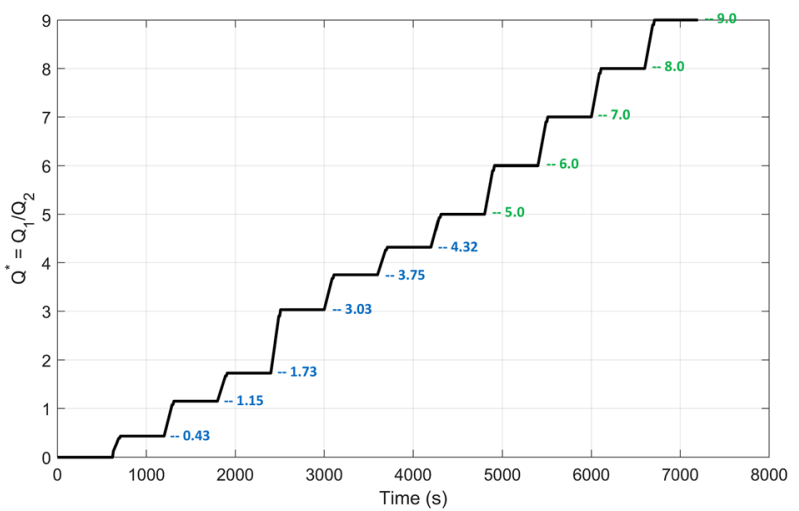

In the current study, the channel and sill geometry under investigation in the BOM simulations is the same configuration as considered previously within the experimental study by Cuthbertson et al. [3] (see Figs. 1 and 2 in this previous paper), where a submerged trapezoidal sill in a rectangular channel restricts the bi-directional exchange flow generated between freshwater $I$ and saline water $M$ basins. The key dimensions of this sill-channel arrangement in the equivalent BOM model domain are: sill crest height $h_{s}=0.5 \mathrm{~m}$; sill crest length $L=2.0 \mathrm{~m}$; sill approach slopes $\alpha_{s}=26.57^{\circ}$; overall channel length $L_{T}=9.0 \mathrm{~m}$; and channel-sill width $B=1.5 \mathrm{~m}$. [Note: full details of the physical system under investigation, as well as the experimental set-up and parametric conditions considered in the Coriolis Rotating Platform facility at Laboratoire des Écoulements Géophysiques et Industriels (LEGI) in Grenoble, are given in Cuthbertson et al. [3]].

Within the BOM model domain representation of this channel-sill arrangement (Fig. 1), the horizontal grid size is $0.1 \mathrm{~m}$ both along and across the channel, while 161 equidistant $\sigma$-layers are used vertically. The grid resolution is much higher vertically than horizontally in order to represent the sharp interface between the dense and fresh water layers. Preliminary tests on grid size dependence by Asplin [31] indicated that the results produced with 161 and 321 vertical layers were almost identical and, as such, the simulations reported in this paper are performed with the former vertical resolution. In addition, as a key focus of the numerical study is on the overall effects of rotation on the exchange flow dynamics across the sill, the selected horizontal grid size of $0.1 \mathrm{~m}$ (i.e. 15 grid cells across the 
channel) was deemed sufficient to facilitate accurate representation of both the tilting interfaces and secondary circulations generated across the top of the sill.

As with the initial configuration in the experimental channel-sill set-up (see [3], the BOM model domain is initially filled with freshwater of density $\rho_{1}=1000 \mathrm{~kg} \mathrm{~m}^{-3}$ and there is no residual flow in the domain. Within the non-rotating BOM simulations, the model parameters are set equivalent to experimental Run 2 conditions [see Table 1 and Cuthbertson et al. [3]]. The volume flux ratio $Q^{*}$ of the freshwater $Q_{1}$ and saline water $Q_{2}$ inflows into the model domain is kept constant at $Q^{*}=0.0$ (i.e. $Q_{1}=0.01 \mathrm{~s}^{-1} ; Q_{2}=6.94 \mathrm{l} \mathrm{s}^{-1}$ ) over the first $600 \mathrm{~s}$ of each BOM simulation before being gradually ramped up (i.e. through incremental increases in $Q_{1}$ values) to a maximum value of $Q^{*}=9.0$ over total run duration of $7200 \mathrm{~s}$. This stepped increase in $Q^{*}$ values is shown in Fig. 2 and extends beyond the range of $Q^{*}$ values (i.e. $Q^{*}=0-4.32$ ) tested in experimental Run 2 (Table 1). Additional non-rotating BOM simulations are then conducted over a range of different $h_{b}$ values (i.e. $h_{b}=0.07-0.59 \mathrm{~m}$ ) to investigate how sill exchange flow dynamics and saline intrusion blocking effects are influenced by the sill submergence depth (while maintaining the same number of $\sigma$-layers in the vertical direction). BOM comparisons with other non-rotating experimental measurements reported in Cuthbertson et al. [3], particularly associated with saline intrusion blockage mechanisms at high $Q^{*}$ values, are also considered through simulation of the Run 7 parameters (see Table 1).

Within all BOM simulations, the time step is set to $0.025 \mathrm{~s}$ to ensure model stability. At both ends of the channel domain, flow relaxation zones (FRS) are added (Fig. 1) to allow smooth inflows and outflows to/from the channel [32]. In the FRS-zone, the velocity and density fields are updated in each time step according to:

$$
\phi=(1-\alpha) \phi_{M}+\alpha \phi_{F R S}
$$

where $\phi$ is one of the velocity components or the density, $\phi_{M}$ is the model value before the relaxation and $\phi_{F R S}$ is the enforced value of the field that is set to ensure the volume fluxes into the interior model domain and/or the density of the inflowing water masses are consistent with the values of the corresponding laboratory experiments (see Table 1). As such, the outflow volume flux near the bottom right hand side of the domain (in basin $I$, see Fig. 1) is set equal to the prescribed lower layer inflow flux of dense water $Q_{2}$ at the bottom left hand side (in basin $M$ ). Similarly, the outflow volume flux near the surface at the left hand side of the domain (in basin $M$ ) is set equal to the prescribed upper layer inflow flux of fresh water $Q_{1}$ at the top right hand side (in basin $I$ ). The density of the outflowing water, at both sides of the domain, is equal to the density in the ambient water $\rho_{a}$ near these outflow regions. It may be noted that within the laboratory experiments a recirculation system was set up in basins $M$ and $I$ that is difficult to mimic in the numerical simulations of the experiments. Consequently, the outflow fluxes are more strongly enforced in the present numerical experiments, and some of the differences between the laboratory measurements and the numerical outputs will, in the discussion, be related to differences in the outflow conditions. The value of the relaxation parameter $\alpha$ (Eq. 1) is set at unity at the outer ends of the FRS zones, and decreases smoothly towards 0 into the interior model domain.

In preliminary numerical experiments, many vertical turbulence schemes, including variants of the Mellor-Yamada scheme [33], have been tested, with the results depending to some extent on the choice of turbulence scheme. However, the vertical profiles of velocity and density were similar in each case and no turbulence model choice allowed the representation of interfacial shear instabilities. It could not be concluded which model choice gave results in better agreement with experimental measurements and therefore it 
Table 1 Summary of main experimental runs and derived parameters [from Cuthbertson et al. [3]] on which BOM simulations were performed

\begin{tabular}{lllllllllll}
\hline Run no. & $\begin{array}{l}\rho_{1} \\
\left(\mathrm{~kg} \mathrm{~m}^{-3}\right)\end{array}$ & $\begin{array}{l}\rho_{2} \\
\left(\mathrm{~kg} \mathrm{~m}^{-3}\right)\end{array}$ & $\begin{array}{l}\Delta \rho \\
\left(\mathrm{kg} \mathrm{m}^{-3}\right)\end{array}$ & $\begin{array}{l}\left(g^{\prime}\right)_{0} \\
\left(\mathrm{~m} \mathrm{~s}^{-2}\right)\end{array}$ & $\begin{array}{l}Q_{1} \\
\left(1 \mathrm{~s}^{-1}\right)\end{array}$ & $\begin{array}{l}Q_{2} \\
\left(1 \mathrm{~s} \mathrm{~s}^{-1}\right)\end{array}$ & $h_{b}(\mathrm{~m})$ & $H(\mathrm{~m})$ & $h_{b} / H$ & $\begin{array}{l}Q^{*} \\
\left(=Q_{1} / Q_{2}\right)\end{array}$ \\
\hline $2^{* \mathrm{a}}$ & 1000.0 & 1005.1 & 5.1 & 0.050 & $0.0-30.0$ & 6.94 & $0.43^{\mathrm{c}}$ & $0.93^{\mathrm{c}}$ & 0.462 & $0.0-4.32^{\mathrm{b}}$ \\
$7^{*}$ & 1000.0 & 1004.7 & 4.7 & 0.046 & $0.0-30.0$ & 6.94 & 0.349 & 0.849 & 0.411 & $0.0-4.32^{\mathrm{b}}$ \\
\hline
\end{tabular}

${ }^{*}$ Test runs for non-rotating $(f=0)$ BOM simulations

${ }^{\mathrm{a}}$ Test conditions on which rotating $(f>0)$ BOM simulations was based

${ }^{\text {b } V a l u e s ~ e x t e n d e d ~ u p ~ t o ~} Q^{*}=9.0$ for BOM simulations (by increasing $Q_{1}$ up to $62.461 \mathrm{~s}^{-1}$ )

${ }^{\mathrm{c}}$ Sill submergence depth $h_{b}$ varied systematically (through $H$ ) in BOM simulations (i.e. $h_{b}=0.07-0.59 \mathrm{~m}$ )

was decided to use the standard Mellor-Yamada scheme (a typical choice for $\sigma$-models) to compute the values of vertical diffusivity and viscosity, which are essentially determined by the gradient Richardson number.

Horizontal viscosity $\nu$ and horizontal diffusivity $\kappa$ must, on the one hand, be large enough to avoid artificial instabilities, while, at the same time, be small enough to allow the representation of small scale flow features as well as possible on the spatial grid. With constant values of $\nu$ and $\kappa$ the solutions became generally too smooth and it was decided to compute the horizontal viscosity $\nu$ using a Smagorinsky formulation [34]:

$$
v=C_{M} \Delta x \Delta y\left[\left(\frac{\partial u}{\partial x}\right)^{2}+\frac{1}{2}\left(\frac{\partial v}{\partial x}+\frac{\partial u}{\partial y}\right)^{2}+\left(\frac{\partial v}{\partial y}\right)^{2}\right]^{\frac{1}{2}}
$$

The horizontal diffusivity $\kappa$ is computed by the same equation after replacing coefficient $C_{M}$ with $C_{H}$. In this equation, $u$ and $v$ are the horizontal velocity components and $\Delta x$ and $\Delta y$ are the grid sizes in the $x$ - and $y$-directions (see above), respectively. Initial tests showed that with $C_{M}=0.2$ and $C_{H}=0.05$ the balance discussed above was achieved. These values are in the range recommended by Blumberg and Mellor [35] and Haidvogel and Beckmann [36] and are therefore used in the present set of numerical experiments.

The bottom boundary stress is specified by

$$
\overrightarrow{\tau_{b}}=\rho_{0} C_{D}\left|\overrightarrow{u_{b}}\right| \overrightarrow{u_{b}}
$$

where the drag coefficient $C_{D}$ is given by the logarithmic relationship:

$$
C_{D}=\frac{\kappa^{2}}{\left(\ln \left(z_{b} / z_{0}\right)\right)^{2}}
$$

In Eq. (3), $\overrightarrow{u_{b}}$ is the velocity vector in the lowermost grid cell, which is a half-cell above the bottom in a staggered C-grid model. In Eq. (4), the von Karman constant $\kappa=0.4, z_{b}$ is the distance from the lowermost velocity point to the bottom, and $z_{0}$ is the bottom roughness parameter. To ensure a no-slip condition that gives a logarithmic velocity profile near the bottom boundary, the fraction $z_{b} / z_{0}$ is set to 1.01. For the BOM simulations where Earth rotation effects are included, this bottom boundary condition also gives velocity profiles near the bottom that are in agreement with Ekman theory [14, 37].

The effects of rotation on the stratified exchange flows generated across the sill have also been investigated through new, additional BOM simulations [following the initial work of 
Asplin [31]]. Here, the Rossby number based on the lower saline intrusion flow across the sill is estimated by:

$$
R o=\frac{\bar{u}_{2, \text { sill }}}{f B}
$$

where $\bar{u}_{2 \text {,sill }}$ is the average velocity in the lower saline intrusion layer, $f(=2 \Omega)$ is the Coriolis parameter (where $\Omega$ is the angular velocity of rotation) and $B(=1.5 \mathrm{~m}$ ) is the sill/channel width. It is found that, with the other parametric conditions set as for the non-rotating experimental Run 2 (see Table 1), Ro is approximately unity for $f=0.0267 \mathrm{rad} \mathrm{s}^{-1}$. This initial $f=0 \mathrm{rad} \mathrm{s}^{-1}$ BOM simulation is therefore repeated with $f=0.0267 \mathrm{rad} \mathrm{s}^{-1}(R o \approx 1)$, $f=0.534 \mathrm{rad} \mathrm{s}^{-1}(R o \approx 0.5), f=0.1068 \mathrm{rad} \mathrm{s}^{-1}(R o \approx 0.25)$ and $f=0.2136 \mathrm{rad} \mathrm{s}^{-1}(R o \approx$ $0.125)$. In terms of the required CPU time, each non-rotational and rotational numerical simulation, with an overall run duration of $7200 \mathrm{~s}$ (Fig. 2), takes approximately 3 days to complete on a computer server with 32 Intel Xenon cores/processors running at $2.76 \mathrm{GHz}$.

\section{Results and analysis}

\subsection{Non-rotating exchange flows-experimental \& numerical comparisons}

Previous experimental studies were conducted to measure the bi-directional stratified flow dynamics generated across the submerged sill for a range of parametric conditions in where Earth rotation effects were not considered [see Cuthbertson et al. [3] for full details]. As such, the initial BOM simulations also considered exchange flow conditions generated in the absence of Coriolis effects (i.e. with $f=0$ ) to permit direct comparison to these experimental measurements. The development of bi-directional stratified flows across the sill obstruction were modelled, in both cases, for a range of boundary conditions with netbarotropic forcing either in the upper freshwater layer (i.e. $Q^{*}=Q_{1} / Q_{2}>1$ ) or in the lower saline layer (i.e. $Q^{*}<1$ ). The corresponding fresh-to-saline flux ratio $Q^{*}{ }_{\text {sill }}=Q_{1 \text {, sill }} / Q_{2 \text {,sill }}$ was obtained at different $x / L$ locations across the sill crest through integration of the measured and computed velocity profiles, such that:

$$
\begin{gathered}
Q_{1, \text { sill }}=\int_{z=h_{2}}^{h_{b}} B u d z \approx B \bar{u}_{1}\left(h_{b}-h_{2}\right) \\
Q_{2, \text { sill }}=\int_{z=0}^{h_{2}} B u d z \approx B \bar{u}_{2} h_{2}
\end{gathered}
$$

where $h_{2}$ is defined by the elevation of the $u=0$ interface. Figure 3 shows the variation in $Q^{*}$ sill over a range of imposed $Q^{*}$ values for Run 2 (Table 1 ) and the results from equivalent BOM simulations. The experimental measurements (i.e. blue data sets) suggest that $Q^{*}{ }_{\text {sill }} \leq Q^{*}$ for $Q^{*} \leq \sim 3.5$, indicating that at lower $Q^{*}$ values, the saline intrusion flux $Q_{2}$ across the sill is dominant and, in some sense, restricts the counterflowing freshwater layer, potentially as a result of freshwater entrainment into the saline intrusion layer. At $Q^{*}>\sim 3.5$, however, the sill flux ratio $Q^{*}$ sill becomes increasingly divergent from $Q^{*}$ such that $Q^{*}{ }_{\text {sill }}>Q^{*}$. This indicates that the magnitude of the upper freshwater flow becomes the dominant entrainment and turbulent mixing mechanism, with the saline intrusion waters increasingly entrained into the counterflowing, upper freshwater layer. Note: in 
experimental runs where the saline intrusion layer is completed blocked at higher $Q^{*}$ values (i.e. $Q_{2 \text {,sill }} \rightarrow 0$; Run 7, Table 1 ), the sill flux ratio $Q^{*}$ sill $\rightarrow \infty$, by definition. It is also interesting to note that the experimental measurements indicate no obvious influence of $x / L$ position across the sill on the magnitude of $Q^{*}$ sill. Equivalent BOM simulations (i.e. red data sets) indicate qualitatively similar trends in $Q^{*}$ sill to the experimental data, with $Q_{\text {sill }}^{*} \leq Q^{*}$ at lower $Q^{*}$ values (i.e. $Q^{*} \leq \sim 4$ ), with $Q^{*}$ sill values diverging from $Q^{*}$ values (i.e. $Q^{*}{ }_{\text {sill }}>Q^{*}$ ) for $Q^{*}>\sim 4$. In general, however, the BOM simulations show considerably less variation in $Q^{*}$ sill values across the sill compared to the experimental data, suggesting more spatially-uniform mixing and entrainment between the counterflowing layers, especially at higher $Q^{*}$ values, due to the diffusive treatment of vertical mixing processes within BOM.

Synoptic $u$-component velocity fields across the sill crest are plotted from analysis of PIV images in Fig. 4(a) for Run 2 (Table 1) with the range of $Q^{*}$ values shown (note: the blank white areas in these plots represent flow regions where poor quality PIV data was obtained due, for example, to shadows or reflections). These plots indicate that as the imposed freshwater flux $Q_{1}$ increases, and corresponding velocity of the upper fresh layer increases (i.e. $u_{1}=0.0 \rightarrow \sim 6.0 \mathrm{~cm} \mathrm{~s}^{-1}$ ), the thickness $h_{2}$ of the lower saline intrusion layer (defined by the $u=0$ velocity contour) tends to be suppressed, as expected for increasing net-barotropic forcing in the upper layer. The corresponding saline intrusion velocity $u_{2}$ is not shown to diminish significantly $\left(u_{2} \approx 4 \mathrm{~cm} \mathrm{~s}^{-1}\right)$ under the increasingly-dominant upper fresh water flow and, although the saline volume flux across the sill is expected to reduce (i.e. $Q_{2 \text {,sill }}<\mathrm{Q}_{2}$ ), bi-directional stratified flow conditions persist for all $Q^{*}$ values tested $\left(Q^{*}=0.0 \rightarrow 4.32\right.$, Table 1$)$. Corresponding synoptic $u$-component velocity fields obtained from BOM simulations of Run 2 parametric conditions [Fig. 4(b)] indicate qualitatively similar bi-directional exchange flows generated across the sill over the same range of $Q^{*}$ values. However, the predicted saline intrusion fluxes $Q_{2, \text { sill }}$ [calculated from Eq. (2)] are typically higher than in the equivalent experimental measurements (due to larger $h_{2}$ and $u_{2}$ values at equivalent $Q^{*}$ values), while upper fresh layer velocities are also higher $\left(u_{1} \rightarrow 7 \mathrm{~cm} \mathrm{~s}^{-1}\right)$ at larger $Q^{*}$ values [Fig. 4(b) (iii-iv)]. This is potentially indicative of the effects of required assumptions and approximations in the BOM model, namely: (i) the boundary conditions in the model domain to generate fresh and saline water forcing the exchange flow across the sill, and (ii) the interfacial mixing and entrainment processes between the counter-flowing fresh and saline layers across the sill. In terms of the former, the specification of fixed input and output regions for the freshwater inflow/outflow and saline intrusion/removal from the model domain, through the FRS zones at the domain

Fig. 3 Comparison of measured (EXP) and simulated (BOM) volume flux ratios $Q^{*}$ sill ( $\left.=Q_{1, \text { sill }} / Q_{2 \text {,sill }}\right)$ obtained in Run 2 (Table 1 ) at different $x / L$ locations across sill plotted versus imposed volume flux ratio $Q^{*}$ $\left(=Q_{1} / Q_{2}\right)$ at channel and computational domain boundaries

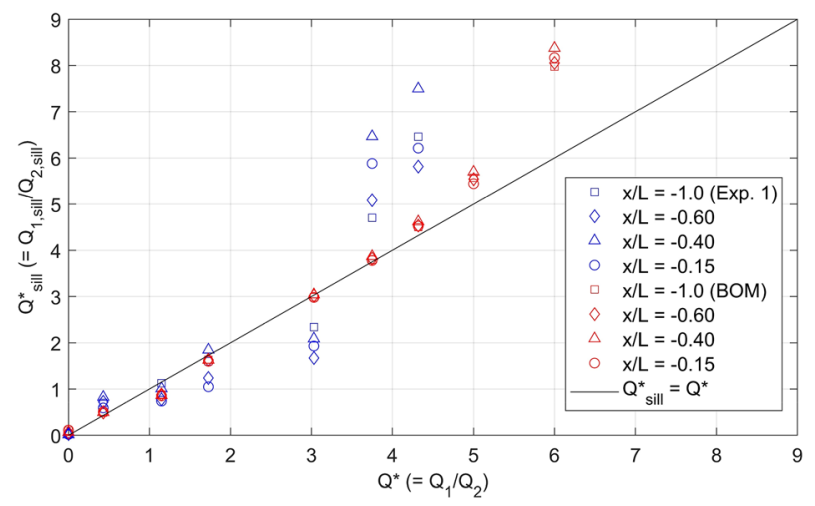


boundary, may have a significant effect on the exchange flow dynamics generated across the sill. In addition, the vertical grid resolution in the model domain is not sufficient to resolve the turbulent structure of the interfacial mixing instabilities (i.e. Kelvin-Helmholz billows or Holmboe waves) and entrainment/detrainment processes occurring at the freshsaline water interface, nor the additional mixing effects associated with sill boundary friction.

Density profiles for the stratified flow conditions generated across the sill were also measured by micro-conductivity probes located at $x / L=0.0,-0.25$ and -0.50 . Figure 5(a) shows the measured density excess $\left[\Delta \rho=\rho(z)-\rho_{1}\right]$ profiles obtained in Run 2 at the mid-point across the sill (i.e. $x / L=-0.5$ ) under different values of the imposed flux ratio $Q^{*}$. These profiles suggest a largely two-layer density structure is generated across the sill (especially at higher $Q^{*}$ values) with turbulent mixing confined to the interfacial shear region between the counter-flowing fresh and saline layers, and with evidence of dense water entrainment into the upper freshwater layer at $Q^{*}=3.75$ and 4.32 . It is noted here that the lower layer density excess increases as $Q^{*}=0.0 \rightarrow 3.75$, indicating that the full density excess (i.e. $\Delta \rho=5.1 \mathrm{~kg} \mathrm{~m}^{-3}$ ) is not established until later in the experimental run. This is a result of initial mixing and dilution of the inflowing saline water source flux

(a)
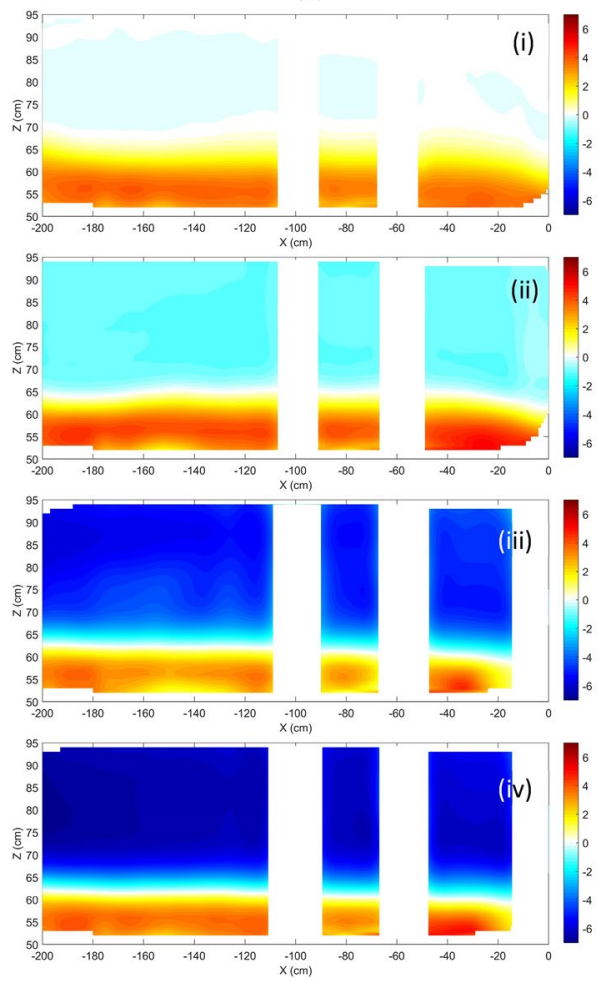

(b)
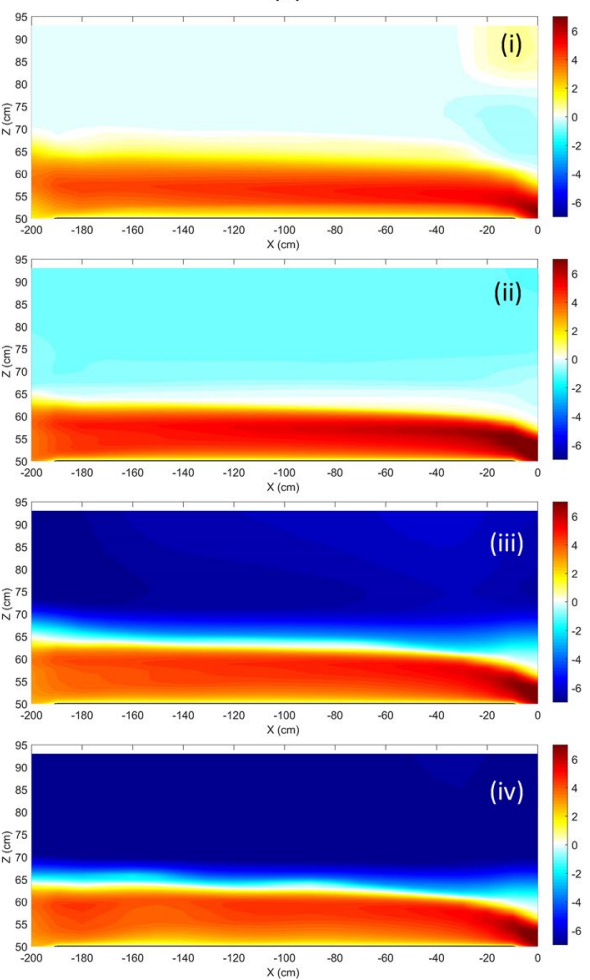

Fig. 4 Comparison of synoptic velocity fields ( $u$-component) generated across the sill from (a) experimental measurements (Run 2, Table 1) and b BOM simulations with no rotation $(f=0)$ for $Q^{*}=Q_{1} / Q_{2}$ values of (i) 0.0 ; (ii) 0.43 ; (iii) 3.75 ; and (iv) 4.32. Blank white areas in experimental plots represent flow regions with poor quality PIV data (e.g. due to shadows or reflections) 
$Q_{2}$ during the initial infilling of basin $M$ prior to spill across the sill (Fig. 1). This effect is successfully simulated in the equivalent BOM simulations of Run 2 density profiles at $x / L=-0.5$ [Fig. 5(b)] by specifying the initial measured density structure in basin $M$ as a model boundary condition. Overall, the predicted density profiles at the mid-point in the sill $(x / L=-0.5)$ show good qualitative agreement with the experimental measurements, again indicating a largely two-layer flow structure. As indicated previously, the grid resolution in the BOM model domain is not sufficient to resolve the detailed turbulent structure of shear-driven mixing at the saline-fresh water interface. However, the degree of mixing between the counter-flowing fresh and saline water layers at higher $Q^{*}$ values $\left[Q^{*}=3.75\right.$ and 4.32, Fig. 5(b)] is indicated by the approximately linearly stratified water formed in the interfacial region.

Divergence between the experimental measurements and BOM simulations arises when assessing the specific parametric conditions under which complete blockage of the saline intrusion layer occurs across the sill. Figure 6(a) shows synoptic $u$-component velocity fields from Run 7(e) and (f) immediately prior to and following blockage (i.e. at $Q^{*}=3.03$ and 3.75 , respectively). It is noted here that the only significant parametric difference between Run 2 [where no significant saline intrusion blockage was observed up to $\left[Q^{*}=4.32\right.$ - see Fig. 4(a)] and Run 7 [where complete blockage occurs at $\left[Q^{*}=3.75-\right.$ see Fig. 6(a)] is the total flow depth $H$ and, hence, the sill submergence depth $h_{b}$ (i.e. $h_{b}=0.43 \mathrm{~m}$ and $0.35 \mathrm{~m}$, respectively). The corresponding BOM simulation for Run 7 parametric conditions is required to reach $Q^{*}=7.0$ before similar complete blockage of the saline intrusion layer occurs [Fig. 6(b)]. This suggests that the saline blockage mechanism predicted by BOM, which has the appearance of an arrested salt-wedge on the sill crest (e.g. [6], with the dominant upper fresh water flow $\left(u_{1} \approx-7.0 \mathrm{~m} . \mathrm{s}^{-1}\right)$ preventing the intruding saline water from spilling into impoundment basin $I$, is markedly different from the observed saline blockage mechanism in Run 7. Specifically, the experimental results [Fig. 6(a)] suggest that the lower saline intruding layer is eroded completely by the counter-flowing upper fresh layer at significantly lower $Q^{*}$ values, while the measured velocity field has no well-defined wedge structure as observed in the BOM simulations. These differences may again reflect a discrepancy between the treatment of interfacial mixing and outflow boundary conditions in the BOM simulations, compared to the experimental result.

Figure 7(a) presents the measured density excess $\Delta \rho$ profiles at three locations along the sill $(x / L=0.0,-0.25$ and -0.5$)$ under the specific conditions (i.e. Run $7(f): Q^{*}=3.75$, Table 1) that resulted in blockage of the saline intrusion layer. This plot shows significant instabilities generated by mixing and entrainment of the remaining saline intrusion layer
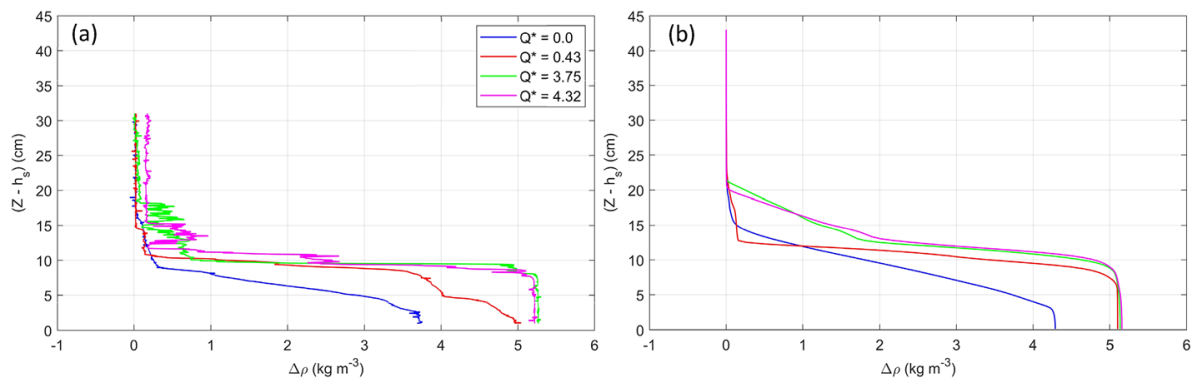

Fig. 5 Comparison of a experimental measurements b BOM simulations of density excess profiles across the sill at mid-point (i.e. $x / L=-0.5$ ) from Run 2 (Table 1) and for $Q^{*}=Q_{1} / Q_{2}$ values shown 
into the upper fresh water at mid-sill locations $x / L=-0.50$ and -0.25 , with corresponding reductions in the maximum excess density $\Delta \rho$ observed in the lower saline water layer. By contrast, at the end of the sill adjacent to impoundment basin $I$ (i.e. $x / L=0.0$ ), the density excess $\Delta \rho$ diminishes almost completely, thus representative of the saline layer blockage condition. Again, direct comparison of these experimental measurements with equivalent BOM simulations (at the higher $Q^{*}=7.0$ value required for blockage of the saline intrusion) [Fig. 7(b)], indicates that the level of mixing observed in the measured profiles is not replicated in the BOM simulations. However, spatial variability in the predicted density excess profiles between the three $x / L$ positions across the sill (and particularly of the saline blockage at $x / L=0.0$ ) shows good qualitative agreement with the experimental measurements [Fig. 7(a)].

Figure 8(a) shows the influence of relative sill depth $h_{b} / H$ on the fraction of the saline inflow flux $Q_{2}$ that is transported across the sill (i.e. $Q_{2 \text {,sill }} / Q_{2}$ ) for a range of inflow flux ratios $Q^{*}=Q_{1} / Q_{2}$ tested in the experimental runs (Table 1 ). This plot also presents the BOM simulations conducted over a wide range of $h_{b} / H(=0.075-0.634)$ and $Q^{*}$ $(=0.0-9.0)$ values. The overall trend from these simulations is that $Q_{2 \text {,sill }} / Q_{2}$ reduces monotonically as $Q^{*}$ increases (i.e. as the freshwater inflow flux $Q_{1}$ increases), with total saline intrusion blockage (i.e. $Q_{2 \text {,sill }} / Q_{2}=0$ ) achieved at lower $Q^{*}$ values as the relative sill submergence depth $h_{b} / H$ reduces (e.g. $Q_{2 \text {,sill }} / Q_{2}=0$ at $Q^{*}=1.15$ when $h_{b} / H=0.075$ and $Q^{*}=9.0$ when $h_{b} / H=0.441$, see Fig. 8). Overall, the experimental data for Runs 2, 3, 4 and 7 (see Table 1 in [3]), also plotted in Fig. 8(a), show a similar monotonic reduction in $Q_{2 \text {,sill }} / Q_{2}$ as $Q^{*}$ values increase, with a qualitatively similar parametric influence of $h_{b} / H$, as shown in the BOM simulations. However, it is clear that the reduction in saline intrusion flux across the sill is far more pronounced in the experiments than in equivalent numerical simulations (i.e. at similar values of $h_{b} / H$ ). This is due to the increased mixing and saline water entrainment observed between the counter-flowing fresh and saline water layers across the sill than is predicted in the BOM simulations. This is also indicated by the

(a)
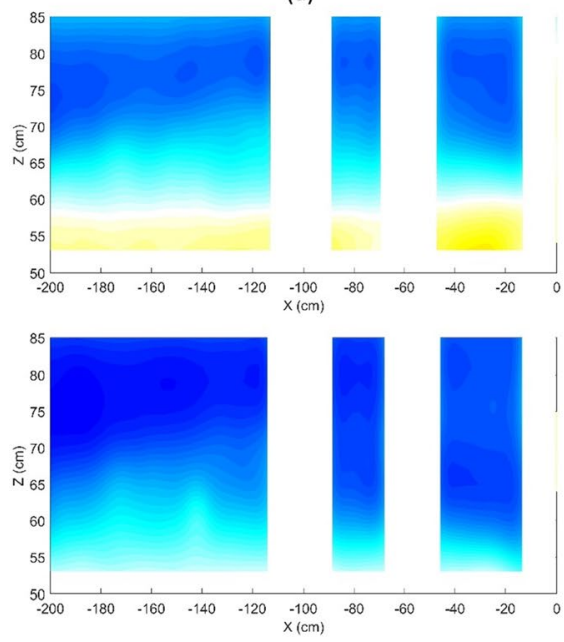

(b)
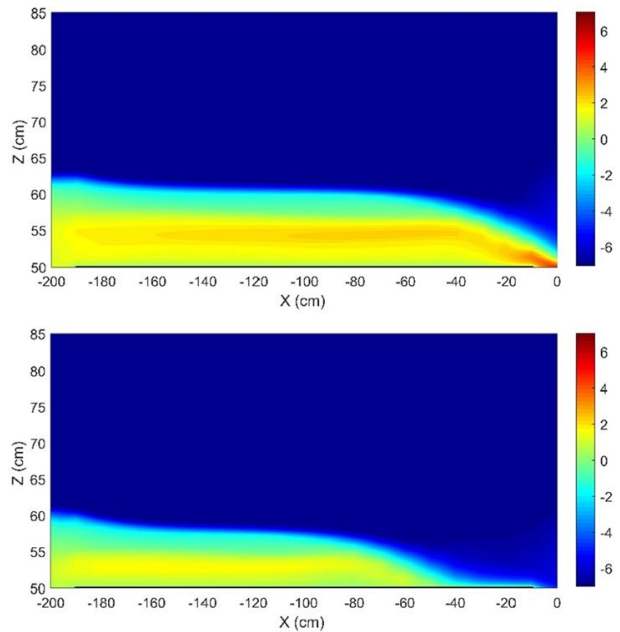

Fig. 6 Comparison of synoptic velocity fields ( $u$-component) prior to and after saline blockage across the sill for (a) experimental measurements [Run 7(e) and (f): $Q^{*}=3.03$ and 3.75; Table 1] and (b) equivalent BOM simulations at the higher $Q^{*}$ values (i.e. $Q^{*}=6.0$ and 7.0) required for blockage 
lower $Q^{*}$ values at which saline blockage occurs in the experiments [i.e. $Q_{2, \text { sill }} / Q_{2}=0$ at $Q^{*}=3.75$ for $h_{b} / H=0.411$ ] compared to the BOM simulations [i.e. $Q_{2, \text { sill }} / Q_{2}=0$ at $Q^{*}=8.0$ for $\left.h_{b} / H=0.419\right]$.

It is possibly more intuitive to plot the saline flux fraction $Q_{2, \text { sill }} / Q_{2}$ across the sill versus the relative sill submergence depth $h_{b} / H$ for different values of the inflow volume flux ratio $Q^{*}$ (i.e. imposed net-barotropic flow boundary condition) [see Fig. 8(b)]. Within this plot, all $Q_{2, \text { sill }} / Q_{2}$ values greater than unity indicate a net-detrainment from the upper freshwater layer into the lower intruding saline water layer, thus increasing flux $Q_{2 \text {,sill }}$ relative to the inflow flux $Q_{2}$. Overall, the plot indicates that the $Q_{2, \text { sill }} / Q_{2}$ is typically reduced as $h_{b} / H$ reduces [i.e. becoming an increasingly restricted region of exchange (RRE)] or as $Q^{*}$ increases (i.e. increasingly dominant net-barotropic flow in the upper freshwater layer). Comparison with experimental data from Runs 2, 3, 4 and 7 (see Table 1 in [3]) again shows qualitative agreement with these trends, but demonstrates significantly greater restriction in the saline intrusion flow $Q_{2 \text {,sill }}$ across the sill at relatively higher sill submergence depths $h_{b} / H$ and lower inflow volume flux ratios $Q^{*}$ than predicted in the BOM simulations.

In general, the findings from the experimental studies and numerical simulations confirm that the relative sill submergence depth $h_{b} / H$, along with the net-barotropic flow condition (defined by $Q^{*}$ ) have primary control on the magnitude of the saline water intrusion flux $Q_{2 \text {,sill }}$ entering into impoundment basin $I$. In the context of stratified exchange flow conditions generated across submerged fjordic sills, these findings have considerable implications for potential flushing and deep-water renewal within semi-enclosed fjordic basins (see discussion below).

\subsection{Rotating exchange flows-computational simulations}

In order to explore the effect of rotation on the exchange flows generated across the sill, a series of BOM simulations were conducted at the laboratory scale set-up with $H$ : $h_{b}=0.93: 0.43 \mathrm{~m}$ (i.e. Run 2 conditions, Table 1). Here, however, the Coriolis parameter $f=2 \Omega$ was initially set at $f=0.0267 \mathrm{rad} \mathrm{s}^{-1}$ (corresponding to $R o \approx 1$ ), then doubled to $f=0.0534 \mathrm{rad} \mathrm{s}^{-1}(R o \approx 0.5), 0.1068 \mathrm{rad} \mathrm{s}^{-1}(R o \approx 0.25)$ and $0.2136 \mathrm{rad} \mathrm{s}^{-1}(R o \approx 0.125)$. Within each different $f$-value run, $Q^{*}=Q_{1} / Q_{2}$ was ramped up from $0.0 \rightarrow 9.0$ through a series of $600 \mathrm{~s}$ increments (run duration: $7200 \mathrm{~s}$, Fig. 2).
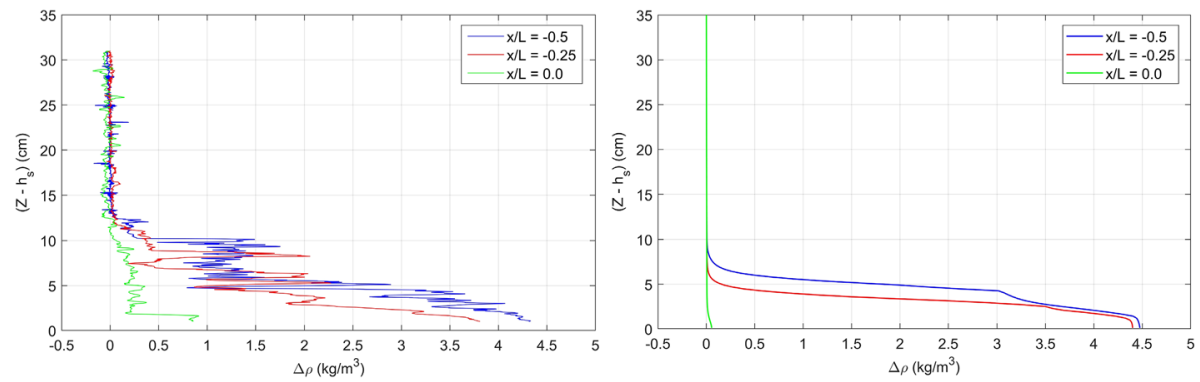

Fig. 7 Comparison of density excess profiles across the sill at the saline blockage condition (i.e. $Q_{2, \text { sill }} \rightarrow 0$ ) from (a) experimental measurements [Run 7(f): $Q^{*}=3.75$; Table 1] and (b) equivalent BOM simulations (at higher $Q^{*}=7.0$ ) at the $x / L$ sill locations shown 

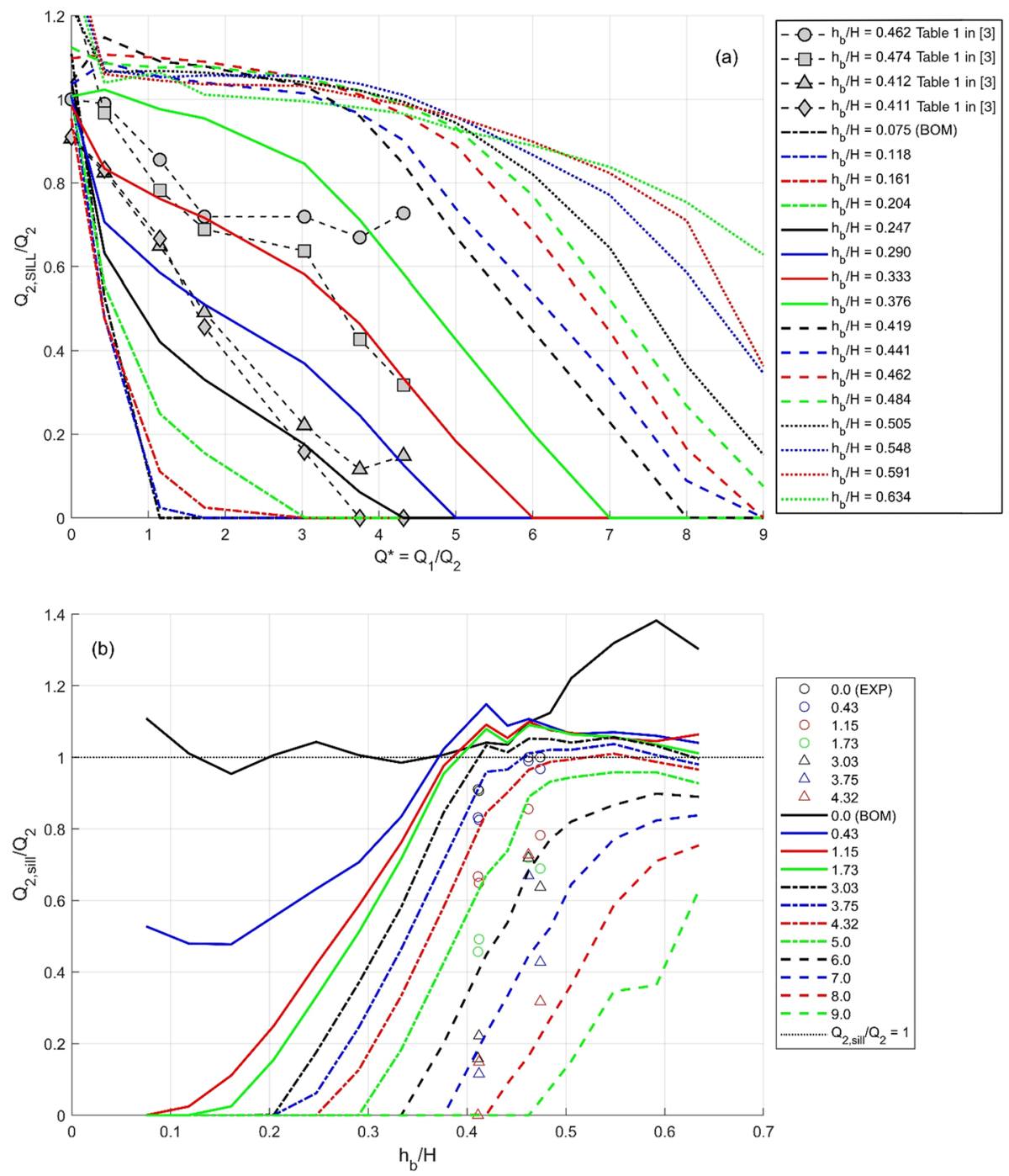

Fig. 8 Predicted fractional reduction in saline intrusion flux across sill $Q_{2, \text { sill }} / Q_{2}$ versus (a) inflow flux ratio $Q^{*}=Q_{1} / Q_{2}$ (for $h_{b} / H$ values shown) and (b) relative sill submergence depth $h_{b} / H$ (for $Q^{*}$ values shown). Corresponding experimental data from Runs 2, 3, 4 and 7 (see Table 1 in [3]) plotted for comparison purposes in both cases

The main characteristics of the geostrophic adjustment in dense water overflows across the sill are shown in Fig. 9 for the $f=0.0267 \mathrm{~s}^{-1}$ run, in which the cross-channel density contour fields [Fig. 9(a)] and corresponding $(U, V, W)$ velocity fields [Fig. 9(b)] are plotted at the mid-sill location (i.e. $x / L=-0.5$ ) for a range of different $Q^{*}$ values. Under the initial $Q^{*}=0$ condition [Fig. 9(a)(i)], the density field shows that the isopycnals (plotted at $\Delta \rho^{\prime}=0.5 \mathrm{~kg} \mathrm{~m}^{-3}$ intervals) are increasingly well-separated as $y \rightarrow 0.0 \mathrm{~m}$, whilst converging as $y \rightarrow 1.5 \mathrm{~m}$. It is also noted that, as with the equivalent non-rotating BOM simulation 
[Fig. 5(b)], the full lower layer density excess $\left(\Delta \rho=5.1 \mathrm{~kg} \mathrm{~m}^{-3}\right)$ is not established immediately in the saline water overflow across the sill as the numerical simulations were setup to mimic the initial mixing and dilution observed within the equivalent non-rotating experimental density profiles [Fig. 5(a)]. The cross-channel density structure of divergent and convergent isopycnals for $y \rightarrow 0 \mathrm{~m}$ and $y \rightarrow 1.5 \mathrm{~m}$, respectively, is observed to a lesser or greater extent at all $Q^{*}$ values, while the cross-channel slope and elevation of the $\rho^{\prime}=2.5 \mathrm{~kg} \mathrm{~m}^{-3}$ isopycnal [shown as black dashed lines in Fig. 9(a)] increases as $Q^{*}$ increases, until the dense water overflow becomes almost completely blocked at $Q^{*}=8.0$ [Fig. 9(a)(v)].

The corresponding velocity structure of the exchange flow is also shown in Fig. 9(b) as a contour plot for the along-channel velocity component $U$ and a velocity vector field for cross-channel and vertical velocity components $V$ and $W$, respectively. At $Q^{*}=0.0$ [Fig. 9(b)(i)], the core of high along-channel velocity $U$ in the saline intrusion layer occurs in the region where isopycnals are most converged (i.e. $U_{\max }=5.65 \mathrm{~cm} \mathrm{~s}^{-1}$ at $y=1.35 \mathrm{~m}, z=0.058 \mathrm{~m}$ ), while reducing in magnitude across the channel as the isopycnals become more divergent (i.e. as $y \rightarrow 0.0 \mathrm{~m}$ ). A similar along-channel velocity structure is observed for $Q^{*}=0.43$ [Fig. 9(b)(ii)], with a larger $U_{\max }=6.55 \mathrm{~cm} \mathrm{~s}^{-1}$ occurring at $y=1.45 \mathrm{~m}$ and $z=0.069 \mathrm{~m}$ due to the full density excess $\left(\Delta \rho=5.1 \mathrm{~kg} \mathrm{~m}^{-3}\right)$ of the saline intrusion having become established across the sill [Fig. 9(a)(ii)]. However, as $Q^{*}$ increases to 3.75 [Fig. 9(b)(iii)], the maximum $U$ velocity in the saline layer begins to reduce $\left(U_{\max }=5.45 \mathrm{~cm} \mathrm{~s}^{-1}\right.$ at $\left.y=1.35 \mathrm{~m}, z=0.071 \mathrm{~m}\right)$, with the high velocity region tending to migrate more towards the centre of the sill. These trends are repeated at $Q^{*}=6.0$ [Fig. 9(b)(iv)] (where $U_{\max }=3.95 \mathrm{~cm} \mathrm{~s}^{-1}$ at $y=0.95 \mathrm{~m}$ and $z=0.055 \mathrm{~m}$ ), indicating that the lower layer volume flux reduces as the saline intrusion layer across the sill is increasingly blocked by the stronger freshwater flow. Finally, at $Q^{*}=8.0$, the maximum saline intrusion velocity has diminished significantly (i.e. $U_{\max }=2.62 \mathrm{~cm} \mathrm{~s}^{-1}$ at $y=0.05 \mathrm{~m}, z=0.028 \mathrm{~m}$ ) for net-barotropic exchange flow conditions in which the saline intrusion is almost completely blocked by the strong freshwater flow. This increasing dominance of the upper freshwater flow is also demonstrated by the reduction in elevation of the $U=0.0 \mathrm{~m} \mathrm{~s}^{-1}$ interface level [red dashed lines, Fig. 9(b)] as $Q^{*}$ values increase. In addition, the velocity contours around this $U=0.0 \mathrm{~m} \mathrm{~s}^{-1}$ interface level are shown to become more tightly-packed as $Q^{*}$ increases [Fig. 9(b)(iv-v)], thus indicative of the stronger shear layer that is generated between the counterflowing saline intrusion and strengthening upper freshwater flows.

In terms of secondary cross-channel motions, at $Q^{*}=0.0$, the cross-channel velocity $V$ is typically negative in both the lower saline intrusion and upper ambient freshwater layers, except for a thin boundary layer at the sill where the $V$ values are positive [Fig. 9(b) (i)]. These features of the cross-channel flow velocity are clearly driven by Coriolis forcing that deflects the saline intrusion flow to the right (looking in the flow direction), while the near sill boundary flow reversal is representative of the development of an Ekman boundary layer (thickness $\delta z=0.031 \mathrm{~m} ; v_{E}=3.1 \mathrm{~mm} \mathrm{~s}^{-1}$ max.). At $Q^{*}=0.43$, the crosschannel velocity $V$ within the upper layer becomes positive due to deflection of the alongchannel freshwater current to the right [Fig. 9(b)(ii)]. The bottom Ekman boundary layer also increases slightly in thickness and velocity (i.e. $\delta z=0.034 \mathrm{~m} ; v_{E}=3.4 \mathrm{~mm} \mathrm{~s}^{-1}$ max.) due to larger along-channel velocities $U$ generated in the saline intrusion layer. At larger $Q^{*}$ values (i.e. $Q^{*}=3.75$ and 6.0), the Ekman boundary layer remains well-defined (with $\delta z=0.039 \mathrm{~m}$ and $v_{E}=3.3-3.8 \mathrm{~mm} \mathrm{~s}^{-1}$ max.), while a large clockwise circulation is generated in the upper freshwater layer [Figs. 9(b)(iii-iv)]. Finally, at $Q^{*}=8.0$, the deflection to the right of the remaining portion of the saline intrusion flux across the sill has diminished with the largely positive $V$ values in the lower layer generated by the dominant clockwise 
(a)
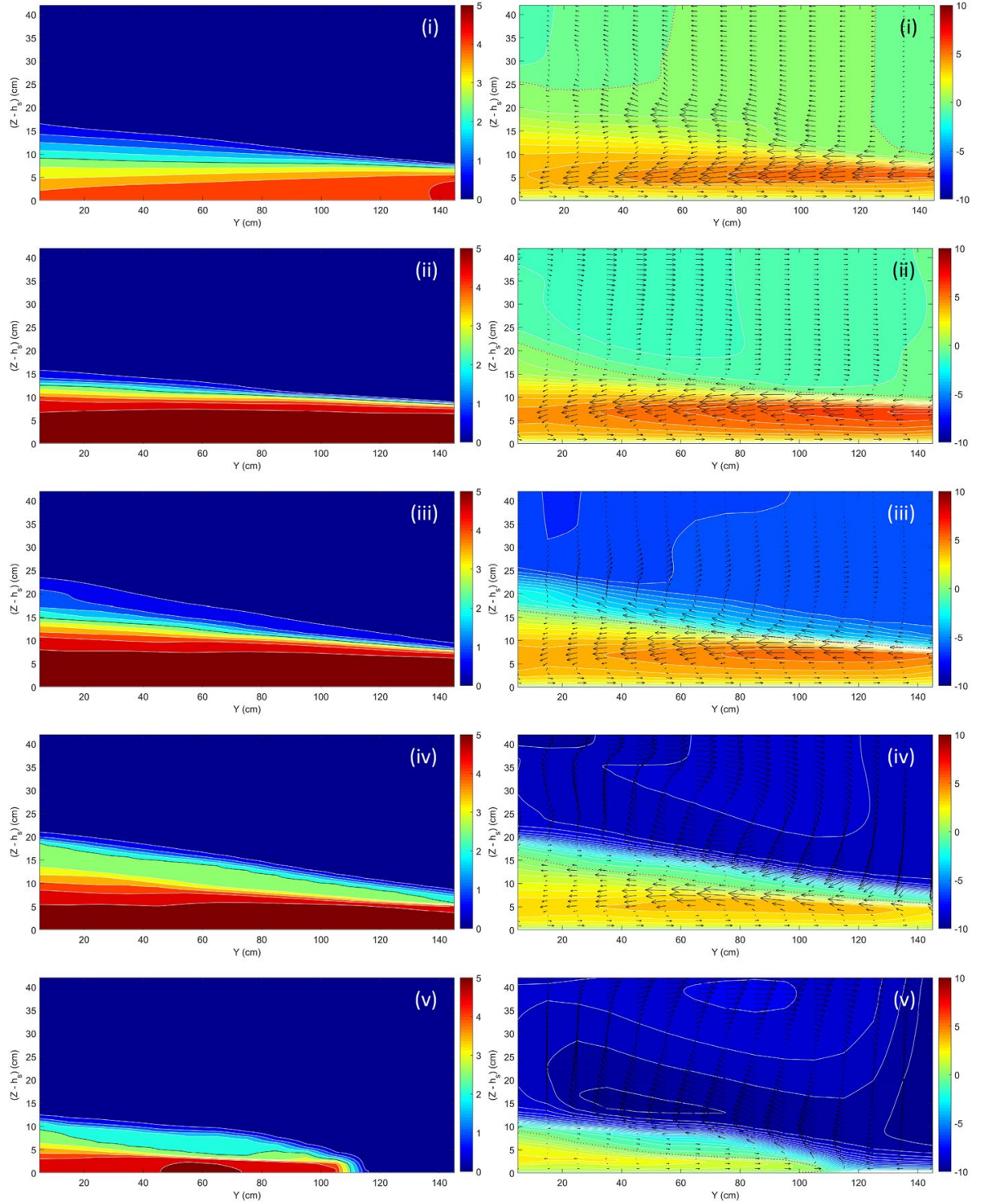

Fig. 9 Cross-channel contour plots at mid-sill of (a) density field (isopycnal contours at $\Delta \rho^{\prime}=0.5 \mathrm{~kg} \mathrm{~m}^{-3}$ intervals, $\Delta \rho^{\prime}=2.5 \mathrm{~kg} \mathrm{~m}^{-3}$ contour shown in black) and (b) along-channel $U$ velocity field (contours at $\Delta U=1 \mathrm{~cm} \mathrm{~s}^{-1}, U=0 \mathrm{~cm} \mathrm{~s}^{-1}$ contour shown as - - ) with cross-channel $V$ and vertical $W$ velocity vector field, for BOM simulations with $Q^{*}: f$ values of (i) $0.0: 0.0267 \mathrm{~s}^{-1}$; (ii) $0.43: 0.0267 \mathrm{~s}^{-1}$; (iii) 3.75 : $0.0267 \mathrm{~s}^{-1}$; (iv) $6.0: 0.0267 \mathrm{~s}^{-1}$; (v) $8.0: 0.0267 \mathrm{~s}^{-1}$

circulation in the upper freshwater layer that erodes the leading edge of the saline wedge layer at $y \approx 1.1 \mathrm{~m}$ [Fig. 9(b)(v)].

Figures 10(i), (ii) and (iii) show the cross-channel density contour and $(U, V, W)$ velocity contour and vector fields for the respective exchange flow conditions generated under 
higher rotation rates (i.e. $f=0.0534,0.1068$ and $0.2136 \mathrm{rad} \mathrm{s}^{-1}$ ) where the saline intrusion is almost completely blocked by the dominant upper freshwater flow. [Note: direct comparison can also be made with Fig. $9(\mathrm{v})$ where $f=0.0267 \mathrm{rad} \mathrm{s}^{-1}$ ]. It is noted that complete blockage of the saline intrusion across the sill occurs at the subsequent $Q^{*}$ increment from the values shown in Fig. 10 and [Fig. 9(v)], and it is clear that, as the Coriolis parameter $f$ increases, this full blockage occurs at lower values of $Q^{*}$ (i.e. $Q^{*}=9.0,8.0,7.0$ and 5.0 for $f=0.0267,0.0534,0.1068$ and $0.2136 \mathrm{rad} \mathrm{s}^{-1}$, respectively). It is also interesting to note that the full saline intrusion blockage condition for the equivalent non-rotating BOM simulation occurs at $Q^{*}=9.0$ [i.e. $f=0.0 \mathrm{rad} \mathrm{s}^{-1} ; h_{b} / H=0.462$, Fig. 8(a)]. In terms of the cross-sill density structure, the isopycnals become steeper and the leading edge of the saline wedge layer recedes as the rotation effects are increased [i.e. $y \approx 1.0 \rightarrow 0.6 \rightarrow 0.2 \mathrm{~m}$ as $f=0.0534 \rightarrow 0.1068 \rightarrow 0.2136 \mathrm{rad} \mathrm{s}^{-1}$, Fig. 10(a)(i)-(iii)]. In all cases, the maximum along-channel velocities within the remaining portions of the saline intrusion layers occur at $y=0.0 \mathrm{~m}$ [Fig. 10(b)(i)-(iii)], with remaining evidence of the Ekman layer generated at the bottom of the saline layer still observed. Large negative cross-channel velocities generated in the counter-flowing freshwater layer above the sill are also associated with Ekman dynamics. These appear to detach from the near-sill boundary flow region at the leading edge of the saline intrusion wedge, forming part of the complex secondary circulations that are generated in the dominant freshwater layer.

Figure 11 shows the variation in the fraction of saline intrusion flux $Q_{2 \text {,sill }} / Q_{2}$ flowing across the sill versus the fresh-to-saline water volume flux ratio $Q^{*}=Q_{1} / Q_{2}$ imposed at the boundaries of the BOM computational domain for varying values of the Coriolis parameter $f$. This plot clearly indicates how the effect of increasing rotation (i.e. increased $f$ values) reduces significantly the overall fraction of saline water flux entering the domain that is transported across the sill. For example, at $Q^{*}=4.0$, for non-rotating conditions (i.e. $f=0.0 \mathrm{rad} \mathrm{s}^{-1}$ ), the fraction $Q_{2, \text { sill }} / Q_{2} \approx 1.0$ meaning that virtually all saline water entering the system is transported across the sill. However, as the rotation increases from $f=0.02$ $67 \rightarrow 0.0534 \rightarrow 0.1068 \rightarrow 0.2136 \mathrm{rad} \mathrm{s}^{-1}$, the resulting intrusion fraction $Q_{2 \text {,sill }} / Q_{2}$ reduces from $\sim 0.89 \rightarrow \sim 0.73 \rightarrow \sim 0.40 \rightarrow \sim 0.11$, suggesting that between 11 and $89 \%$ of the total saline water input is blocked under increasing rotation effects. From direct comparison with Fig. 8(a), the effect of increasing rotation from $f=0.0-0.2136 \mathrm{rad} \mathrm{s}^{-1}$ appears to have a comparable blocking effect (i.e. in terms of the fractional reduction in the saline intrusion flux transported across the sill) to a decrease in the relative sill submergence depth (i.e. under non-rotating flow conditions, $f=0.0 \mathrm{rad} \mathrm{s}^{-1}$ ). Again, at $Q^{*}=4.0$ in Fig. 8(a), Q2 ${ }_{\text {,sill }} / Q_{2} \approx 1.0$ when $h_{b} / H=0.462$ (i.e. $h_{b}=0.43 \mathrm{~m}$ ), but reduces to $\sim 0.91 \rightarrow \sim 0.65 \rightarrow \sim 0$. $40 \rightarrow \sim 0.20$ as $h_{b} / H$ reduces from $0.419 \rightarrow 0.376 \rightarrow 0.333 \rightarrow 0.290$ (i.e. $h_{b}=0.39 \rightarrow 0.35 \rightarrow$ $0.31 \rightarrow 0.27 \mathrm{~m})$.

\section{Discussion}

\subsection{Non-rotating sill exchange flows}

Previous experimental studies [3] had attempted to define the parametric conditions under which saline intrusion blockage occurred for non-rotating conditions only (i.e. $f=0$ ). This preliminary analysis demonstrated that, for the range of conditions tested, saline blockage occurred at a specific value of the densimetric Froude number $F_{1}{ }^{2}=q_{1}{ }^{2} /\left(g_{0}^{\prime} h_{b}{ }^{3}\right)>\sim 0.125$ for the freshwater flow across the sill (i.e. where layer thickness $h_{1}=$ submergence depth 
(a)
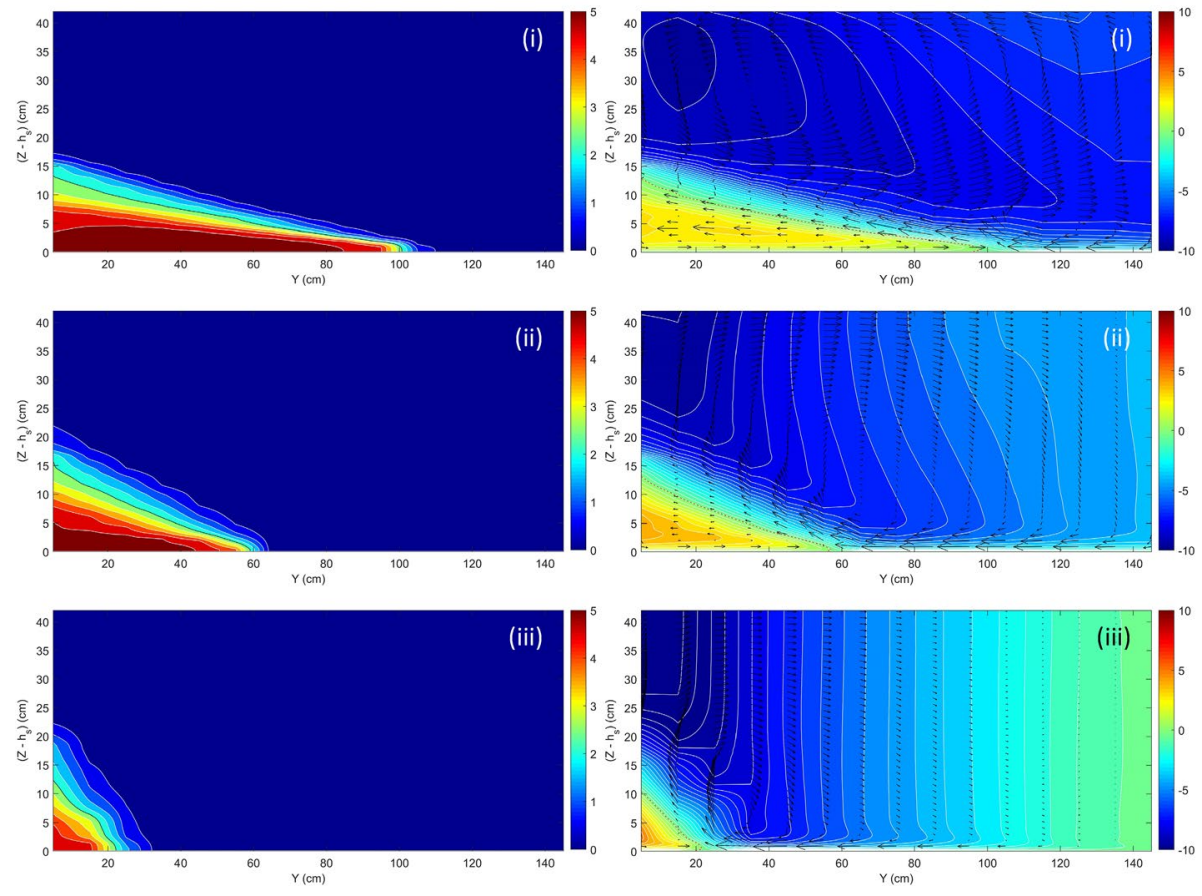

(b)
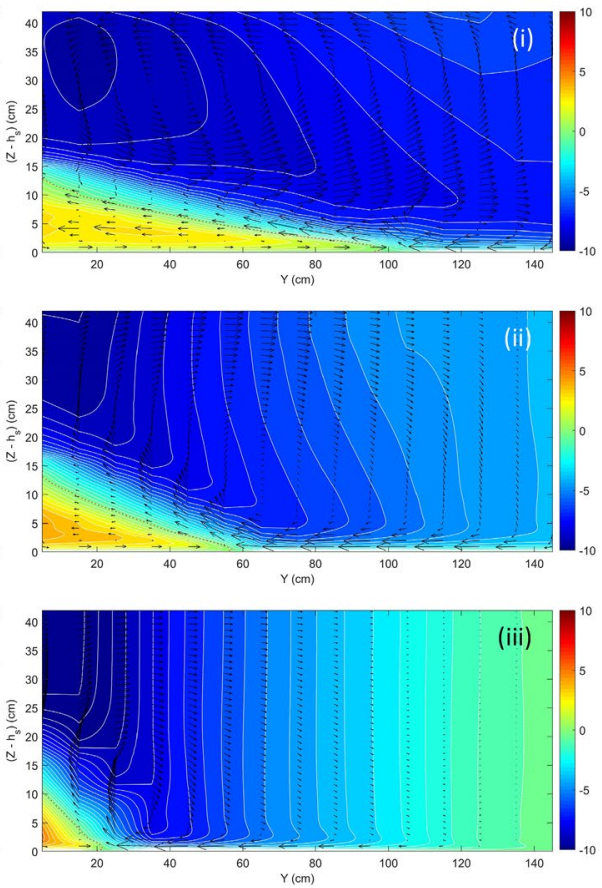

Fig. 10 Caption as for Fig. 9, for BOM simulations with $Q^{*}: f$ values of (i) 7.0: 0.0534; (ii) 6.0: 0.1068; (iii) 5.0: 0.2136. [Also compare Fig. 9(v): $Q^{*}: f=8.0: 0.0267$ ]

$h_{b}$ ), irrespective of the relative magnitude of the source fresh and saline volume fluxes (i.e. $\left.Q^{*}=Q_{1} / Q_{2}=q_{1} / q_{2}\right)$. This suggested that saline intrusion blockage requires a specific combination of a large freshwater volume flux $q_{1}\left(=Q_{1} / B\right)$ and/or lower submergence depth $h_{b}$ and reduced gravity $g_{0}^{\prime}$. Specifically, the two experimental runs from Cuthbertson et al. [3] in which full saline blockage occurred (i.e. Runs 6 and 7, see Table 1 in [3]) were initiated at $Q^{*}=8.90$ and 3.75, respectively, for otherwise identical conditions (i.e. $g_{0}^{\prime}=0.046 \mathrm{~m}$. $\mathrm{s}^{-2}, h_{b}=0.35 \mathrm{~m}$ ). It is interesting to note here that a similar freshwater densimetric Froude number $F_{0}$ was defined by Sargent and Jirka [6] in their analysis of saline wedge formation (i.e. an arrested saline intrusion) generated by counterflowing fresh and saline water masses along a horizontal, rectangular channel. Overall, they found that the flow dynamics in the saline wedge were controlled primarily by the freshwater overflow, with a narrow range of Froude numbers $\left(F_{0}=0.389-0.491\right)$ at which the stationary salt wedges formed. Within the current study, full blockage of the saline intrusion layer across the sill was measured at $F_{1}=0.383$ and 0.392 (for Runs 6 and 7, respectively, see Table 1 in [3]), where there was also clear evidence from the density profiles [i.e. Figure 7(a) for Run7(f)] that an arrested saline wedge developed on the sill between $x / L=0.0$ and -0.5 .

For the equivalent non-rotating BOM simulations, the formation of an arrested saline wedge along the horizontal sill crest was demonstrated clearly both from velocity fields [e.g. Figure 6(b)] and density profiles [Fig. 7(b)]. However, a primary motivation of conducting these numerical simulations was to investigate in greater detail the sensitivity of the saline blockage condition to the relative sill submergence depth $h_{b} / H$ over a 
Fig. 11 Predicted fractional reduction in saline intrusion flux across sill $Q_{2, \text { sill }} / Q_{2}$ versus inflow flux ratio $Q^{*}=Q_{1} / Q_{2}$ showing effect of increasing rotation effects (i.e. Coriolis $f$ values)

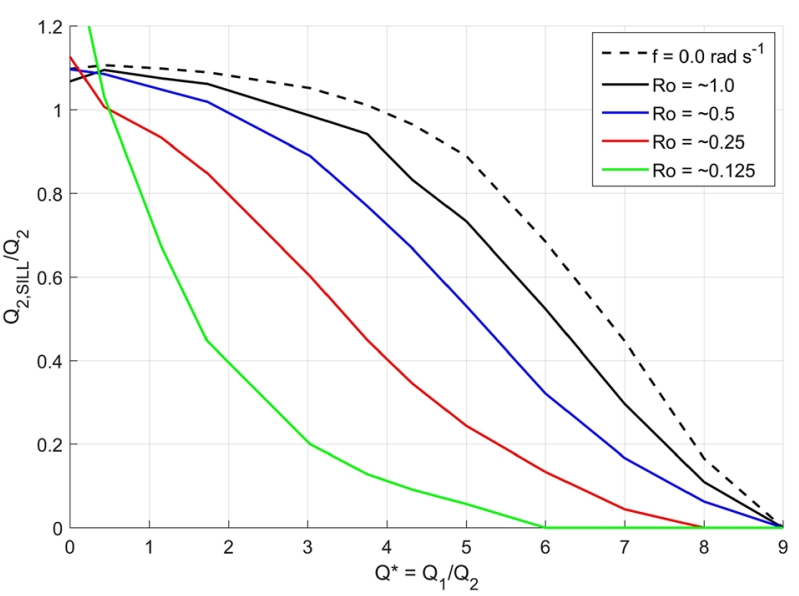

wider range (i.e. $h_{b} / H=0.075-0.634$ ) than considered in the experimental study (i.e. $h_{b} / H=0.411-0.474$, Table 1). In this context, the numerical results shown in Fig. 8(a) indicated that full saline blockage (i.e. an arrested saline intrusion with $Q_{2 \text {,sill }} / Q_{2}=0$ ) occurred when $Q^{*}=1.15 \rightarrow 9.0$ for $h_{b} / H=0.075 \rightarrow 0.462$ (i.e. $h_{b}=0.07-0.43 \mathrm{~m}$ for $H=0.93 \mathrm{~m}$ ). The corresponding upper freshwater Froude numbers $F_{1}$ for these blockage conditions ranged from $F_{1}=1.29 \rightarrow 0.66$ (i.e. $Q_{1}=8.0 \rightarrow 62.61 . \mathrm{s}^{-1} ; g_{0}^{\prime}=0.05 \mathrm{~m} . \mathrm{s}^{-2}$ ), which are considerably higher than observed in the experiments. It is considered likely that these differences arise largely from BOM treatment of interfacial mixing and entrainment fluxes generated between the counterflowing water masses across the sill, as well as its representation of the inflowing and outflowing boundary conditions specified in basins $M$ and $I$. These points are discussed further below.

When we consider the measured local flux ratios $Q^{*}$ sill $=Q_{1, \text { sill }} / Q_{2, \text { sill }}$ generated across the sill in Run 2 (blue data in Fig. 3), it is interesting to note that, at both $Q^{*}=0.0$ and 0.43 , the experimental data typically lies above the straight line suggesting $Q_{\text {sill }}^{*}>Q^{*}$. Thus, under net-barotropic conditions generated in the lower saline intrusion layer $\left(Q^{*}<1\right)$, a counterflowing motion must be induced in the upper layer that enhances the freshwater outflow across the sill [as shown in Fig. 4(a)(i) and (ii)]. By contrast, at $Q^{*}=1.15,1.73$ and 3.03, the local flux ratio $Q^{*}{ }_{\text {sill }}<Q^{*}$ suggesting that the fresh and saline fluxes across the sill are reduced and increased, respectively, in comparison to the source volume fluxes entering the channel. Such conditions may result from a number of scenarios or combination of internal flow mechanisms, including: (i) internal energy losses due to bottom friction and interfacial shear between the counterflowing layers (e.g. [38, 39]), resulting in net entrainment of freshwater from the upper layer into the bottom intruding saline layer [5], (ii) the formation of an internal hydraulic control across the sill limiting the freshwater outflow and thus promoting recirculation within basin $I$ [5], and (iii) the saline intrusion spill into impoundment basin $I$ generating sufficient mixing (e.g. via the internal hydraulic jump forming at the bottom of the sill incline) to initiate freshwater entrainment and recirculation in basin $I$, thus limiting the freshwater outflow flux across the sill. Furthermore, when we consider the fractional reduction in the intruding saline volume flux across the sill, $Q_{2, \text { sill }} / Q_{2}$, as presented in Fig. 8(a), we observe that $Q_{2 \text {,sill }} / Q_{2}$ typically decreases monotonically with increasing $Q^{*}$ values. This clearly indicates that the saline intrusion across the sill is also lower than the salt water volume flux into basin $M$, again most probably 
associated with internal friction losses across the sill obstruction, the potential formation of a hydraulic control at the sill, thus limiting salt water intrusion, and consequently the development of salt water recirculations in basin $M$. Referring back to Fig. 3, at higher $Q^{*}$ values of 3.75 and 4.32 , the sill flux ratio is now $Q^{*}$ sill $>Q^{*}$, indicating that the freshwater outflow becomes dominant (i.e. strong net-barotropic flow in the upper layer that controls the bidirectional exchange flow across the sill). This local sill flux condition again may again develop from a number of possible scenarios, including: (i) a net entrainment of saline water from the lower intruding layer into the upper freshwater layer due to strong interfacial mixing, and (ii) partial blockage and recirculation of the inflowing saline water flux in basin $M$ due to the strength of the freshwater outflow across the sill. This saline water blockage and circulation in basin $M$ may also be promoted by the pumped abstraction (i.e. outflow) of the upper freshwater layer at the end of the channel, directly above the salt water inflow into basin $M$ (Fig. 1). The effect of interfacial mixing and the entrainment of saline water by the dominant upper freshwater outflow can be shown by comparing $Q^{*}$ sill values at different $x / L$ locations along the sill (different symbols in Fig. 3). While this effect is not entirely clear in Run 2, it was demonstrated in other runs that $Q^{*}{ }_{\text {sill }}$ values typically increase along the sill length (from basin $M \rightarrow$ basin $I$ ) under higher $Q^{*}$ conditions [see Fig. 8 in Cuthbertson et al. [3]].

Comparing again the experimental data with equivalent data obtained from BOM simulations for Run 2 (red data in Fig. 3), we see that, fundamentally, the same trends in local sill flux ratio $Q^{*}$ sill versus source flux ratio $Q^{*}$ are observed to those described above (i.e. $Q^{*}$ sill $>Q^{*}$ at $Q^{*}=0.0,0.43$ and $>3.75$; and $Q^{*}{ }_{\text {sill }}<Q^{*}$ at $Q^{*}=1.15$ and 1.73 ), albeit these trends are more subtle in the BOM results. The disparity between laboratory measurements and numerical simulations is also demonstrated clearly when comparing equivalent runs from Fig. 8(a) [e.g. grey circles $\left(h_{b} / H=0.462-\right.$ Run 2$)$ and red dashed line $\left.\left(h_{b} / H=0.462-\mathrm{BOM}\right)\right]$. Here, the measured local saline flux across the sill with respect to the saline water inflow is shown to reduce by approximately $30 \%$ (to $Q_{2 \text {,sill }} / Q_{2} \approx 0.7$ ) at a relatively low $Q^{*}=1.73$, before stabilising as $Q^{*}$ increases up to its maximum value of 4.32. By contrast, the equivalent $\mathrm{BOM}$ experiment reveals that $Q_{2, \text { sill }} / Q_{2}$ remains above unity until $Q^{*} \approx 4$, before decreasing steadily to $Q_{2 \text {,sill }} / Q_{2}=0$ (i.e. full saline blockage) at $Q^{*}=9$. These variations between the laboratory and numerical model results are most likely to arise from differences in the BOM treatment of internal friction (i.e. interfacial mixing and bottom boundary roughness) across the sill and the imposed inflow/outflow boundary conditions at the edges of the model domain within basins $M$ and $I$ (see Sect. 2.1) that are clearly different from the laboratory set-up (see Sect. 2.2). In a sense, the semienclosed laboratory configuration of basin $M$ and the open boundary of basin $I$ is the opposite of what might typically be expected in a real fjordic setting (where a submerged sill separates a semi-enclosed fjordic basin from the open sea boundary.

In summary, within both the non-rotating laboratory and numerical experiments, the saline intrusion across the sill is first restricted and then fully blocked with increasing $Q^{*}$ values (i.e. increasing freshwater flow $Q_{1}$ ), while the key topographic controlling parameter is the sill submergence depth $h_{b}$. Within Fig. 8, where the effect of $h_{b}$ on saline intrusion blockage is clearly demonstrated, this topographic sill parameter has been normalised by the total basin depth $H$. However, it could be argued that the sill length $L$ would be expected to have more influence on the exchange flow dynamics [e.g. through boundary friction effects $[1,40]]$ than the overall basin depth $H$. In the current laboratory and numerical experiments, the sill length $L$ was kept constant at $2 \mathrm{~m}$ and thus the variability in $L / h_{b}(=4.44-5.71$ and 3.39-28.6, respectively) was associated solely with changes to 
submergence depth $h_{b}$. This compares with $L / H=4.68$ for the dimensions of the rectangular channel used in the arrested salt wedge experiments by Sargent and Jirka [6].

It is also interesting to compare these experimental $L / h_{b}$ values with equivalent values for topographic sills within Norwegian and Scottish fjords. In Scotland, Loch Etive has a total of six sills along the length of the loch, averaging $15 \mathrm{~m}$ in depth. The largest of these sills, separating the deep inner basin (maximum depth $145 \mathrm{~m}$ ) from the shallower outer basins (maximum depth $\sim 65 \mathrm{~m}$ ), has a maximum sill depth $h_{b}=13 \mathrm{~m}$ and crest length $L=210 \mathrm{~m}$ (i.e. $L / h_{b}=16.2$ ) $[1,2]$. The exchange across this relatively shallow sill is controlled by tidal barotropic forcing and results in a dominant mode-I baroclinic response within the stratified upper basin [1]. High freshwater runoff into the upper basin also contributes to the strong basin stratification, contributing to periods of restricted basin circulation and reduced tidal intrusion across the sill, which limits deep water renewal and increases the likelihood of hypoxic/anoxic conditions in bottom basin waters. Similar hypoxic/anoxic basin waters are also commonly experienced in Norwegian fjords, including, for example, Iddefjorden at the border of Norway and Sweden [41]. Here, the mouth of the Iddefjord basin has two narrow sills $(L \sim 70 \mathrm{~m})$ with submergence depths $h_{b} \sim 7 \mathrm{~m}$ (i.e. $L / h_{b} \approx 10$ ), separated by a wider and deeper small basin [40]. Again, tidal exchange flow dynamics across the sills are controlled by a combination of bottom friction effects, barotropic form drag and the baroclinic response in the basin. Recent simulations in Masfjorden (Norway) by Aksnes et al. [42] have also indicated a decrease in the rate of deep water renewal events (i.e. ventilation of basin waters) associated with reduced tidal intrusion across the submerged sill $\left(h_{b}=70 \mathrm{~m} ; L \sim 500 \mathrm{~m} ; L / h_{b} \approx 7\right)$ at the entrance to the deep Masfjorden basin (maximum depth $494 \mathrm{~m}$ ). The simulations suggest this reduction is associated with the ongoing warming of North Atlantic Waters (NAW) leading to a reduction in the density of the seawater intrusion, which is expected to result in prolonged anoxic conditions in Masfjorden basin within 7-12 years [42]. In all these cases, the exchange flow dynamics (and seawater intrusion, in particular), along with the resulting impacts on basin stratification, circulation and water quality, are thus strongly controlled by the sill topography, with the aspect ratios $L / h_{b}$ of the fjordic sills found to coincide with the range of $L / h_{b}$ values tested in the current laboratory and numerical simulations.

\subsection{Rotating sill exchange flows}

Within most fjordic scenarios, the overall exchange flow dynamics are unlikely to be affected to any significant extent by Earth rotation effects (i.e. Coriolis forces), as this requires the width of fjordic basin (and sill region) to be larger than the Rossby radius of deformation [10]. In the context of larger scale oceanographic flows, however, Coriolis forces are known to deflect counterflowing water masses passing through sea channels and ocean straits [e.g. Gibraltar Strait [43], Baltic Sea Channel [44]] or deep water density currents flowing down the continental margins of oceans [e.g. Faroe Bank Channel [45], Darelius and Fer [46]]. Many experimental and analytical studies have been conducted into the fundamental effects of rotation on salinity-driven gravity currents, making important contributions in defining the geostrophic adjustment of topographically-constrained currents (e.g. $[11,12,18,47,48]$,the flow velocity structure and turbulence intensities (e.g. $[17,49,50]$, and the role of Ekman boundary layers in the development of secondary flow circulations (e.g. $[14,15,51,52]$. Nonetheless, there remains open questions regarding the effects of rotation on the dynamics of bi-directional exchange flows within topographicallyconstrained settings (e.g. across submerged sills), particularly in relation to (i the transverse 
distribution of counter-flowing water masses across the sill; (ii geostrophic adjustment in bi-directional exchange flow layers; (iii secondary circulations and boundary (Ekman layer development; and (iv the saline blockage conditions under strong net-barotropic flows in the upper freshwater layer. For this purpose, the numerical experiments within the current study were extended to consider the effect of Coriolis forces on all these aspects of exchange flow dynamics in the same idealised sill-basin configuration as tested in the nonrotating experiments.

The main effects of rotation on the transverse density structure of the exchange flows [Figs. 9(a) and 10(a)] are demonstrated by the inclination of the density interface [represented by the $\Delta \rho^{\prime}=2.5 \mathrm{~kg} \mathrm{~m}^{-3}\left(\rho^{\prime}=0.5\right)$ isopycnal] and convergence of isopycnals in the positive $y$ direction across the sill. Both of these effects are indicative of the geostrophic adjustment within the sill exchange flows. This is confirmed by comparing the transverse density interface inclination angle $\alpha_{\rho^{\prime}=0.5}$ (i.e. inclination of the $\rho^{\prime}=\Delta \rho^{\prime} /\left(\rho_{2}-\rho_{1}\right)=0.5$ isopycnal) with the expected transverse slope $\alpha_{g}$ at which the exchange flow is geostrophically balanced, $\alpha_{g} \approx f \cdot\left(\bar{u}_{2}-\bar{u}_{1}\right) /\left(g^{\prime}\right)_{0}$ (where $\bar{u}_{1}$ and $\bar{u}_{2}$ are representative average velocities in the upper and lower layers) (Fig. 12). It should be noted that although $\alpha_{\rho^{\prime}=0.5} \approx \alpha_{g}$ in the majority of the runs, at higher $f$ values (corresponding to lower $R o$ values) the agreement between $\alpha_{g}$ and $\alpha_{\rho^{\prime}=0.5}$ values reduces, especially at higher $Q^{*}$ values. This is at least partly due to the average velocity $\bar{u}_{1}$ calculated for the upper fresh layer including a flow region [where $u_{1} \approx 0$, e.g. see Fig. 10(b)(iii)] that appears to have little or no influence on the geostrophic adjustment in the lower saline intrusion layer. For such runs, better agreement is gained with $\alpha_{g} \approx f .\left(u_{2}-u_{1}\right)_{\max } /\left(g^{\prime}\right)_{0}$ (as plotted for these runs in Fig. 12). The observed isopycnal convergence or "pinching" in the positive $y$ direction has been described in previous experimental studies of dense water outflows through topographically-constrained channels (e.g. [11, 12, 18] and in field survey measurements (e.g. [45, 53-55], of dense water overflows at the sill constriction in the Faroe Bank Channel. Johnson and Sanford [56] suggested that this wedged-shaped density field (and isopycnal pinching) was induced by secondary cross-channel circulations and mixing driven by the development of bottom and interfacial Ekman layers.

Evidence of these bottom Ekman layers is detected in all modelled rotating sill exchange flows in the current study [e.g. Figs. 9(b) and 10(b)], with a thin cross-channel sill boundary flow directed in the positive $y$ direction (i.e. to the left, looking downstream). By contrast, the presence of the interfacial Ekman layer in the same cross-channel direction is only detected in certain runs [e.g. Fig. 9(b)(iv) and (v)]. Furthermore, the interior of the lower saline intrusion layer is shown to flow in the negative cross-channel $y$ direction (i.e. $y \rightarrow 0$ ), representative of the main sill intrusion flow being directed to the right (looking downstream) (as expected for rotating sill overflows in the Northern Hemisphere), which acts as a volume balance to the boundary Ekman layers. Qualitatively similar secondary circulations, as described in detail in Cossu et al. [17], have been observed in several laboratory experiments considering density current flows along rotating channels and canyons (e.g. [14, 15, 49, 52] and reported in field studies of ocean gravity currents (e.g. [56-58]. In the bi-directional exchange flows considered in the current study, the outflowing upper freshwater layer is also directed to the right (looking downstream) at lower $Q^{*}$ values [e.g. Fig. 9(b)(ii) and (iii)], while as $Q_{1}$ increases, large scale secondary circulation cells develop [e.g. Fig. 9(b)(iv) and (v)] with the freshwater sill outflow following spiral motions. This finding is again consistent with the previous experimental study of Johnson and Ohlsen [16], who found that the secondary helical circulations generated by friction and rotation effects (i.e. interfacial and solid-boundary Ekman layers) led to a reduction in the twolayer exchange through a semi-circular channel, compared to the equivalent non-rotating, 
Fig. 12 Geostrophic adjustment in rotating sill exchange flow characterised by predicted cross-channel density interface slope $\alpha_{\rho^{\prime}=0.5}$ [i.e. slope of $\rho^{\prime}=\Delta \rho^{\prime} /\left(\rho_{2}-\rho_{1}\right)=0.5$ isopycnal;- - — contours in Figs. 9(a) and $10(\mathrm{a})$ ] and calculated geostrophic slope $\alpha_{g} \approx f\left(u_{2}-u_{1}\right) /\left(g^{\prime}\right)_{0}$

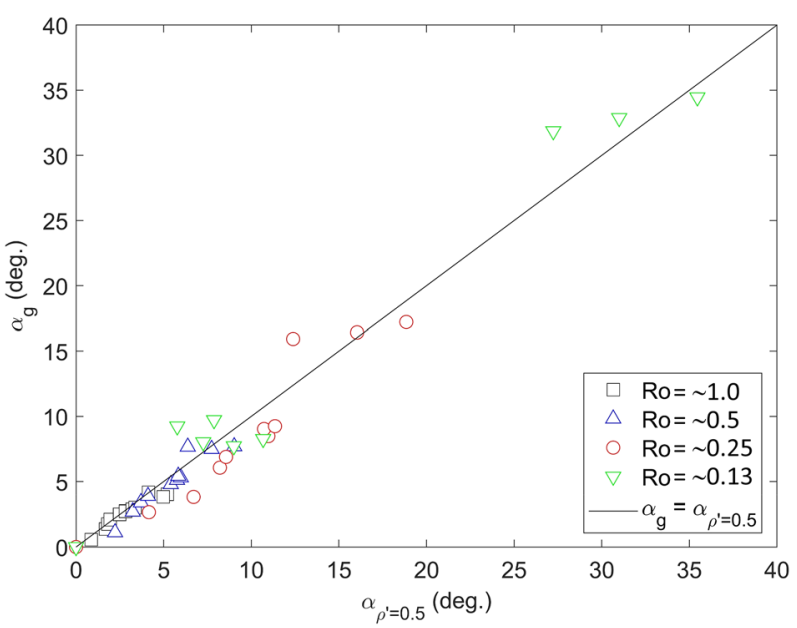

two-layer exchange flow case. Similar measurements of the transverse velocity structure have been made for density currents flowing along a rotating straight rectangular channel [17] and within rotating V-shaped laboratory-scale ridges and canyons [14, 49]. The studies also showed that the secondary circulations generated in the density currents, due to rotation and friction effects, resulted in the flow being substantially slower than in equivalent non-rotating currents due to the helical motions of dense water parcels (i.e. longer flow paths taken) as they travel along the channel/canyons.

In the current rotating sill exchange flow experiments, a significant reduction in the saline intrusion flux ratio across the sill $Q_{2 \text {,sill }} / Q_{2}$ was also observed (Fig. 11) as both the source flux ratio $Q^{*}$ and the Coriolis parameter $f$ increased (i.e. the latter corresponding to a reduction in $R o$ ). It is interesting to note that when $R o \approx 1$ (corresponding to the $f=0.0267 \mathrm{~s}^{-1}$ run in Fig. 11), the effect of rotation results in only a relatively small reduction in the saline intrusion flux ratio $Q_{2 \text {,sill }} / Q_{2}$ compared to the equivalent non-rotating run (i.e. $f=0.0 \mathrm{~s}^{-1}$, Fig. 11), with full intrusion blockage (i.e. $Q_{2, \text { sill }} / Q_{2} \rightarrow 0$ ) occurring at the same source flux ratio $Q^{*}$. This clearly suggests that for $R o>1$, the geostrophic adjustment in the sill exchange flow will have only marginal effects on the resulting flow properties (e.g. saline intrusion fluxes), which is broadly in agreement with the flow regime transition, defined by Cossu et al. [17], where Ekman boundary layer dynamics become less important. It is also important to note that this $R o=O(1)$ condition is representative of the geostrophically-controlled Mediterranean dense water outflows through the Strait of Gibraltar (e.g. [59] and through the Bosporus Channel into the Black Sea [60], as well as in the Faroe Bank channel overflow at the threshold sill (e.g. [15, 45].

In the current experiments, the relative influence of increasing the Coriolis forces (i.e. through increasing $f$ ) and, hence, reducing the Rossby number to $R o<<1$, is shown to have a clear impact on the magnitude of the saline intrusion flux ratio $Q_{2 \text {,sill }} / Q_{2}$ across the sill. In particular, this can be demonstrated in Fig. 11 where the same overall reduction in $Q_{2, \text { sill }} / Q_{2}$ occurs at significantly lower $Q^{*}$ values when the Coriolis parameter $f$ is increased (i.e. $R o$ is reduced). This Rossby-number-induced blocking effect is shown clearer in Fig. 13(a-d), where the cross-channel flow structure of the bi-directional sill exchange flows at $Q^{*}=3.75$ are plotted with $R o$ values decreasing from $\sim 1 \rightarrow \sim 0.5 \rightarrow \sim 0.25 \rightarrow \sim 0.125$. [Note: the corresponding $Q_{2 \text {,sill }} / Q_{2}$ values reduce from $0.92 \rightarrow 0.77 \rightarrow 0.45 \rightarrow 0.13$, respectively (see 
Fig. 11), with $Q_{2, \text { sill }} / Q_{2} \approx 1$ for the equivalent non-rotating exchange flow condition]. This finding again appears to be general accord with Cossu et al. [17] and others who suggest that, when $R o<<1$, rotating gravity current flows are "substantially slower" than their non-rotating counterparts, and that Ekman boundary layer dynamics should be included in models to describe rotating flow properties when $R o<2$.

It is also apparent from Fig. 13, however, that, although the saline intrusion flux across the sill clearly diminishes as $R o$ decreases (as described above), both the maximum and cross-section average velocities $u_{2 \text {,max }}$ and $\bar{u}_{2}$ within the saline intrusion layers remain relatively consistent over the majority of Ro conditions tested. Indeed, the mean and maximum saline intrusion layer velocities $\bar{u}_{2}$ and $u_{2, \max }$ are shown to only reduce by $\sim 1.1$ and $\sim 1.5 \%$, respectively, as $R o$ reduces from $\sim 1$ to $\sim 0.25$ [Fig.13(a-c)], while $\bar{u}_{2}$ only shows a more significant reduction $(\sim 66 \%)$ at $R o=\sim 0.125$ (i.e. close to the full saline intrusion blockage condition). It is also interesting to observe that the equivalent $\bar{u}_{2}$ and $u_{2 \text {,max }}$ values calculated at the mid-sill location within the equivalent non-rotating sill exchange flow experiment [i.e. $Q^{*}=3.75$, Fig. 4(b)(iii)] are $2 \%$ and $\sim 15 \%$ lower than within the rotating sill exchange run with $R o=\sim 1$. This suggests that, although the overall saline intrusion flux is larger in the non-rotating sill exchange flow (i.e. $Q_{2 \text {,sill }} / Q_{2} \approx 1$ ), $\bar{u}_{2}$ and $u_{2 \text {,max }}$ are reduced due to the larger cross-channel flow area of the saline intrusion across the sill. This finding appears to be consistent at all $Q^{*}$ values tested and suggests a deviation from the hindered flow behaviour of rotating gravity currents described by Cossu et al. [17] and others. This potentially indicates that additional dynamical effects associated with the bi-directional, sill exchange flows considered here result in an increase in the intruding saline layer velocities between the non-rotating and rotating runs, whilst constraining the overall exchange in the latter case (e.g. Johnson and Olsen [16]). It can be hypothesised that the upper fresh layer flow structure and secondary circulations generated, in particular, must impose a strong influence on both the transverse distribution and extent of the saline intrusion flow region across the sill. This effect appears most noticeable at lower $R o$ values [i.e. $R o=\sim 0.25$ and $\sim 0.125$, Fig. 13(c) and (d)], where the maximum outflowing upper layer velocities $u_{1}$ occur in the confined flow region directly above the counter-flowing saline intrusion layer. By contrast, upper layer velocities diminish $u_{1} \rightarrow 0$ in the positive $y$ direction and can even reverse in direction at the opposite side of the sill [i.e. $y>1.2 \mathrm{~m}$, Fig. 13(d)].

\section{Concluding remarks}

The study has investigated the development of stratified exchange flows across a submerged sill obstruction, comparing experimental results from a large-scale laboratory study with equivalent scaled numerical simulations using a non-hydrostatic, $\sigma$-coordinate numerical model [Bergen Ocean Model (BOM)]. These model-scale numerical simulations have then been extended to consider the relative influence of both the sill submergence depth and the Coriolis forces on the dynamics of net-barotropic exchange flows generated across the sill and the parametric conditions under which full blockage of the saline intrusion layer occurs.

Comparison of the laboratory experiments and numerical simulations indicate that the non-rotating sill exchange flow ratio $Q^{*}$ sill $\left(=Q_{1, \text { sill }} / Q_{2 \text {,sill }}\right)$ diverges significantly from the source flux ratio $Q^{*}\left(=Q_{1} / Q_{2}\right)$ imposed at the model boundaries, especially when the net-barotropic flow conditions in the upper freshwater layer become more dominant and increasingly block the lower saline intrusion layer across the sill (i.e. with $Q_{2, \text { sill }} / Q_{2} \rightarrow 0$ ). 

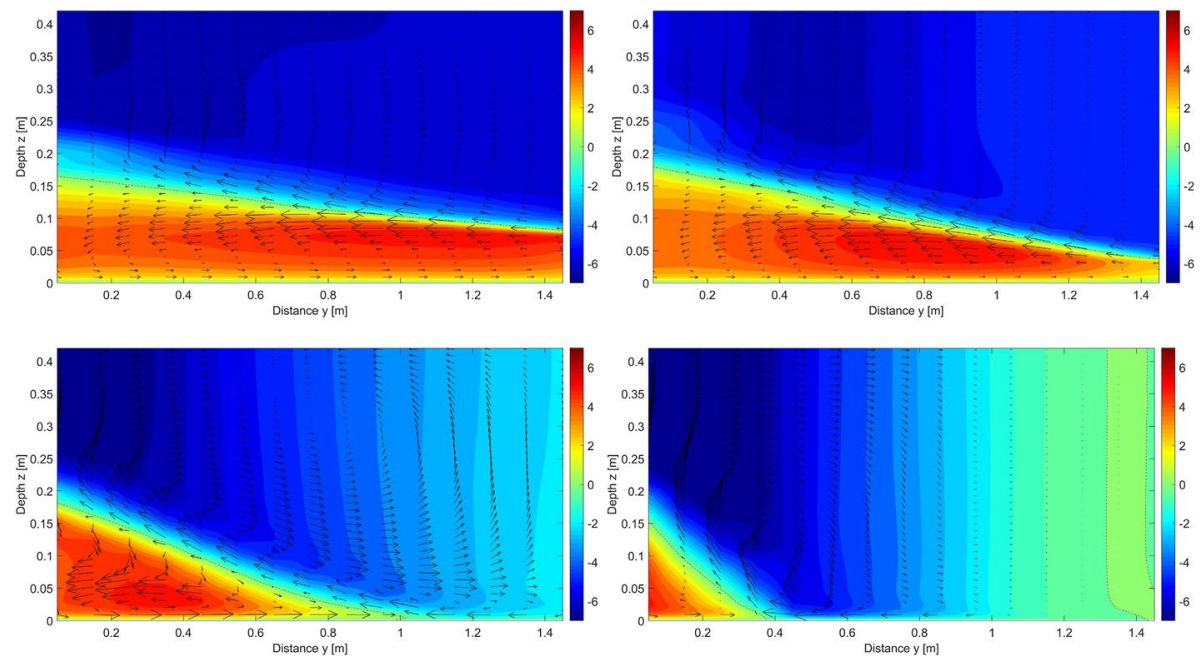

Fig. 13 Comparison of secondary circulations and increasing intrusion blockage for rotating sill exchange flows obtained for a source flux ratio $Q^{*}=3.75$ showing influence of $f\left(\mathrm{rad} \mathrm{s}^{-1}\right)$ : $R o$ values of (a) $0.0267: \sim 1.0$; (b) 0.0534: 0.5; (c) 0.1068: 0.25; and (d) 0.2136: 0.125

The numerical model simulations also extend the parametric conditions considered in the laboratory experiments to investigate a larger range of sill submergence depths $h_{b}$. This parametric study indicates that the topographic sill geometry, and the aspect ratio $L / h_{b}$ in particular, appears to have the dominant control, along with the net-barotropic forcing conditions imposed by $Q^{*}$, on the sill exchange flow and, importantly, the parametric conditions under which full saline intrusion blockage is observed. Variations in the observed sill flux ratios and the parametric conditions required for full saline layer blockage within the laboratory experiments and numerical model runs can be attributed primarily to differences in the outflow boundary conditions and the representation of interfacial mixing and entrainment processes between the counter-flowing fresh and saline water layers across the sill.

The effect of Coriolis forces on the sill exchange flow is shown to lead to increased blockage of the saline intrusion in comparison to the equivalent non-rotating sill exchange flow generated under the same sill submergence depth $h_{b}$ and source flux ratio $Q^{*}$ condition. These numerical simulations suggest that the development of Ekman boundary layers at the sill boundary, as well as strong secondary circulations both within the lower saline intrusion and upper outflowing freshwater layer, act to restrict the saline intrusion flux across the sill. These rotation effects become increasingly important when the Rossby number for the saline intrusion flow $R o<<1$, while conditions where $R o>1$ would appear to have limited effect of the sill exchange flow dynamics when compared to equivalent non-rotating conditions. It is especially interesting to note that while saline intrusion fluxes $Q_{2 \text {,sill }}$ are reduced by increased rotation effects, the average and maximum velocities within the saline intrusion layer are higher than for equivalent non-rotating exchange flows. This suggests that Coriolis forcing in the upper freshwater layer imposes a strong control on the transverse distribution and extent of the lower saline intrusion flow region, resulting in localised acceleration within this lower layer. 
Finally, it is acknowledged that these discussions on rotating sill exchange flows are based purely on numerical simulations of the idealised sill configuration tested in the laboratory experiments conducted under non-rotating conditions only. While many of the key features of the rotating sill exchange flow dynamics are in general qualitative agreement with both previous experimental and field studies of dense gravity flows along rotating channels and/or down submarine canyons, full validation of the current model outputs requires additional laboratory or field data to fully demonstrate, and understand dynamically, the implications of imposed Coriolis forcing on the net-barotropic exchange flows generated within topographic regions of restricted exchange. For this purpose, a future study will utilise the BOM to simulate new experimental data sets obtained at the LEGI Coriolis Rotating Platform facility of rotating bi-directional exchange flows generated in a trapezoidal channel configuration $[61,62]$.

Acknowledgements The experimental part of this work was supported by European Community's Seventh Framework Programme through the grant to the budget of the Integrating Activity HYDRALAB IV within the Transnational Access Activities, Contract No. 261520. The authors would like to thank all researchers involved in this project, as well as the academic and technical staff at Laboratoire des Écoulements Géophysiques et Industriels (LEGI) in Grenoble for their assistance with these experiments. The authors would also like to thank the Scottish Research Partnership in Engineering (SRPe) for the financial support provided to AJSC for two research visits over to the Department of Mathematics at the University of Bergen during 2019 to support this collaboration.

Open Access This article is licensed under a Creative Commons Attribution 4.0 International License, which permits use, sharing, adaptation, distribution and reproduction in any medium or format, as long as you give appropriate credit to the original author(s) and the source, provide a link to the Creative Commons licence, and indicate if changes were made. The images or other third party material in this article are included in the article's Creative Commons licence, unless indicated otherwise in a credit line to the material. If material is not included in the article's Creative Commons licence and your intended use is not permitted by statutory regulation or exceeds the permitted use, you will need to obtain permission directly from the copyright holder. To view a copy of this licence, visit http://creativecommons.org/licenses/by/4.0/.

\section{References}

1. Inall M, Cottier FR, Griffiths C, Wiles P (2004) Sill dynamics and energy transformation in a jet fjord. Ocean Dyn 54:307-314

2. Inall M, Rippeth TP, Griffiths C, Wiles P (2005) Evolution and distribution of TKE production and dissipation within stratified flow over topography. Geophys Res Lett 32:L08607

3. Cuthbertson A, Laanearu J, Carr M, Sommeria J, Viboud S (2018) Blockage of saline intrusions in restricted, two-layer exchange flows across a submerged sill obstruction. Environ Fluid Mech 18:27-57

4. Thorpe SA (1977) Turbulence and mixing in a Scottish loch. Philos Trans Royal Soc Lond 286A:125-181

5. Laanearu J, Cuthbertson AJS, Davies PA (2014) Dynamics of dense gravity currents and mixing in an up-sloping and converging vee-shaped channel. J Hydraul Res 52(1):67-80

6. Sargent FE, Jirka GH (1987) Experiments on saline wedge. J Hydraul Eng 113(10):1307-1323

7. Negretti ME, Zhu DZ, Jirka GH (2007) Barotropically induced interfacial waves in two-layer exchange flows over a sill. J Fluid Mech 592:135-154

8. Negretti ME, Zhu DZ, Jirka GH (2008) The effect of bottom roughness in two-layer flows down a slope. Dyn Atmos Oceans 45(1-2):46-68

9. Fouli H, Zhu DZ (2011) Interfacial waves in two-layer exchange flows downslope of a bottom sill. J Fluid Mech 680:194-224

10. Gill AE (1982) Atmosphere-ocean dynamics. Academic Press, San Diego

11. Cuthbertson AJS, Laanearu J, Wåhlin AK, Davies PA (2011) Experimental and analytical investigation of dense gravity currents in a rotating, up-sloping and converging channel. Dyn Atmos Oceans 52(3):386-409 
12. Cuthbertson AJS, Lundberg P, Davies PA, Laanearu J (2014) Gravity currents in rotating, wedgeshaped adverse channels. Environ Fluid Mech 14(5):1251-1273

13. Maxworthy T (1986) On turbulent mixing across a density interface in the presence of rotation. J Phys Oceanogr 16(6):1136-1137

14. Berntsen J, Darelius E, Avlesen H (2016) Gravity currents down canyons: effects of rotation. Ocean Dyn 66:1353-1378

15. Davies PA, Wåhlin A, Guo Y (2006) A combined laboratory and analytical study of flow through the Faroe bank channel. J Phys Oceanogr 36(7):1348-1364

16. Johnson GC, Ohlsen DR (1994) Frictionally modified rotating hydraulic channel exchange and ocean outflows. J Phys Oceanogr 24:66-78

17. Cossu R, Wells MG, Wåhlin AK (2010) Influence of the Coriolis force on the velocity structure of gravity currents in straight submarine channel systems. J Geophys Res 115:C11016

18. Cuthbertson AJS, Davies PA, Stachchuk N, Vlasenko V (2014) Model studies of dense water overflows in the faroese channels. Ocean Dyn 64(2):273-292

19. Farmer DM, Armi A (1999) Stratified flow over topography: the role of small-scale entrainment and mixing in flow establishment. Proceedings of The Royal Society of London A 455:3221-3258

20. Matthäus W, Lass UH (1995) The recent salt inflow into the Baltic Sea. J Phys Oceanogr 25(2):280-286

21. Berntsen J (2000) USERS GUIDE for a modesplit $\sigma$-coordinate numerical ocean model. Technical Report 135, Dept. of Applied Mathematics, University of Bergen, Johs. Bruns gt.12, N-5008 Bergen, Norway. 48p

22. Berntsen J, Alendal G, Avlesen H, Thiem $\varnothing$ (2018) Effects of the bottom boundary condition in numerical investigations of dense water cascading on a slope. Ocean Dyn 68:553-573

23. Berntsen J, Alendal G, Avlesen H (2019) The role of eddies on pathways, transports, and entrainment in dense water flows along a slope. Ocean Dyn 69:841-860

24. Seim K, Fer I, Berntsen J (2010) Regional simulations of the faroe bank channel over flow using a $\sigma$-coordinate ocean model. Ocean Model 35:31-44

25. Berntsen J, Xing J, Alendal G (2006) Assessment of non-hydrostatic ocean models using laboratory scale problems. Cont Shelf Res 26:1433-1447

26. Berntsen J, Xing J, Davies A (2008) Numerical studies of internal waves at a sill: sensitivity to horizontal size and subgrid scale closure. Cont Shelf Res 28:1376-1393

27. Keilegavlen E, Berntsen J (2009) Non-hydrostatic pressure in $\sigma$-coordinate ocean models. Ocean Model 28:240-249

28. Eliassen I, Heggelund, Y, Haakstad M (2001) A numerical study of the circulation in Saltfjorden, Saltstraumen and Skjerstadfjorden. Cont Shelf Res 21:1669-1689

29. Lynge BK, Berntsen J, Gjevik B (2010) Numerical studies of dispersion due to tidal flow through Moskstraumen, northern Norway. Ocean Dyn 60:907-920

30. Yang H, Przekwas A (1992) A comparative study of advanced shock-capturing schemes applied to Burgers equation. J Comput Phys 102:139-159

31. Asplin M (2018) Numerical studies of rotationally controlled lock exchange flow over a sill. Master's thesis, Department of Mathematics, University of Bergen, Norway

32. Martinsen E, Engedahl H (1987) Implementation and testing of a lateral boundary scheme as an open boundary condition in a barotropic ocean model. Coast Eng 11:603-627

33. Mellor G, Yamada T (1982) Development of a turbulence closure model for geophysical fluid problems. Rev Geophys Space Phys 20:851-875

34. Smagorinsky J (1963) General circulation experiments with the primitive equations, I The basic experiment. Mon Weather Rev 91:99-164

35. Blumberg AF, Mellor GL (1987) A description of a three-dimensional coastal ocean circulation model. In three-dimensional coastal ocean Models, coastal and estuarine series (Heaps, N.S. ed.). Am Geophys Union 4:1-16

36. Haidvogel DB, Beckmann A (1999) Numerical Ocean Circulation Modeling. Series on Environmental Science and Management: Volume 2. Imperial College Press, p 344. ISBN: 978-1-86094-114-6

37. Cushman-Roisin B (1994) Introduction to geophysical fluid dynamics. Prentice Hall, NewJersey (ISBN-0-13-353301-8)

38. Arita M, Jirka GH (1987) Two-layer model of saline wedge I: entrainment and interfacial friction. J Hydraul Eng 113(10):1229-1246

39. Stenström P (2003) Mixing and recirculation in two-layer exchange flows. J Geophys Res 108(C8):3256

40. Stigebrandt A (1999) Resistance to barotropic tidal flow in straits by baroclinic wave drag. J Phys Oceanogr 29:191-197 
41. Bianchi T, Arndt S, Austin W, Benn D et al (2020) Fjords as aquatic critical zones. Earth Sci Rev 203:103145

42. Aksnes D, Aure J, Johansen P-O, Johnsen G, Salvanes A (2019) MultiOdecadal warming of Atlantic water and associated decline of dissolved oxygen in a deep fjord. Estuar Coast Shelf Sci 228:106392

43. Baringer M, Price J (1999) A review of the physical oceanography of the Mediterranean outflow. Mar Geol 155:63-82

44. Kõuts T, Omstedt A (1993) Deep water exchange in the baltic proper. Tellus A: Dyn Meteorol Oceanogr 45(4):311-324

45. Girton JB, Pratt LJ, Sutherland DA, Price JF (2006) Is the faroe bank channel overflow hydraulically controlled? J Phys Oceanogr 36:2340-2349

46. Darelius E, Fer I, Quadfasel D (2011) Faroe bank channel overflow: mesocale variability. J Phys Oceanogr 41:2137-2154

47. Borenäs K, Lundberg P (1986) Rotating hydraulic of flow in a parabolic channel. J Fluid Mech 167:309-326

48. Borenäs K, Lundberg P (1988) On the deep-water flow through the Faroe bank channel. J Geophys Res 93(C2):1281-1292

49. Darelius E (2008) Topographic steering of dense overflows: laboratory experiments with V-shaped ridges and canyons. Deep-Sea Res I 55:1021-1034

50. Keevil GM, Peakall J, Best JL, Amos KJ (2006) Flow structure in sinuous submarine channels: velocity and turbulence structure of an experimental submarine channel. Mar Geol 229:241-257

51. Cossu R, Wells M (2010) Coriolis forces influence the secondary circulation of gravity currents flowing in large-scale sinuous submarine channel systems. Geophys Res Lett 37:L17603

52. Wåhlin A, Darelius E, Cenedese C, Lane-Serff G (2008) Laboratory observations of increased plume entrainment in the presence of submarine canyons and ridges. Deep-Sea Res I 55:737-750

53. Borenäs K, Lake I, Lundberg P (2001) On the intermediate water masses of the faroe-bank channel overflow. J Phys Oceanogr 31:1904-1914

54. Borenäs K, Lundberg P (2004) The faroe-bank channel deep-water overflow. Deep-Sea Res II $51: 335-350$

55. Mauritzen C, Price J, Sanford T, Torres D (2005) Circulation and mixing in the faroese channels. Deep-Sea Res I 52:883-913

56. Johnson GC, Sanford TB (1992) Secondary circulation in the faroe bank channel outflow. J Phys Oceanogr 22:927-933

57. Fer I, Voet G, Seim KS, Rudels B, Latarius K (2010) Intense mixing of the faroe bank channel overflow. Geophys Res Lett 37:L02604

58. Sherwin TJ (2010) Observations of the velocity profile of a fast and deep oceanic density current constrained in a gully. J Geophys Res (Oceans) 115:C03013

59. Davies PA, Guo Y, Rotenburg E (2002) Laboratory model studies of Mediterranean outflow adjustment in the Gulf of Cadiz. Deep-Sea Res II 49:4207-4223

60. Özsoy E, Di Iorio D, Gregg M, Backhaus JO (2001) Mixing in the bosphorus strait and the black sea continental shelf: observations and a model of the dense water outflow. J Mar Syst 31:99-135

61. Adduce C, De Falco MC, Cuthbertson AJS, Laanearu J, Malcangio D, Kaur K, Negretti E, Sommeria J, Valran T, Viboud S (2019) The dynamics of bi-directional exchange flows: implications for morphodynamic change within estuaries. Proceedings of the HYDRALAB+ Joint User Meeting, Bucharest

62. De Falco MC, Adduce C, Cuthbertson A, Negretti ME, Laanearu J, Malcangio D, Sommeria J (2021) Experimental study of uni and bi-directional exchange flows in a large scale rotating trapezoidal channel. Phys Fluids. https://doi.org/10.1063/5.0039251

Publisher's Note Springer Nature remains neutral with regard to jurisdictional claims in published maps and institutional affiliations. 


\section{Authors and Affiliations}

A. Cuthbertson ${ }^{1}$ (D) J. Berntsen ${ }^{2} \cdot$ J. Laanearu ${ }^{3} \cdot$ Magdeli Asplin $^{2}$

J. Berntsen

jarle.berntsen@uib.no

J. Laanearu

janek.laanearu@taltech.ee

Magdeli Asplin

magdeli.asplin@goodtech.no

1 School of Science and Engineering, University of Dundee, Dundee, UK

2 Department of Mathematics, University of Bergen, Bergen, Norway

3 School of Engineering, Tallinn University of Technology, Tallinn, Estonia 